Check for updates

Cite this: RSC Adv., 2019, 9, 13186

Received 12th March 2019

Accepted 23rd April 2019

DOI: 10.1039/c9ra01889a

rsc.li/rsc-advances

\section{Development of double strand RNA mPEI nanoparticles and application in treating invasive breast cancer $\dagger$}

\author{
Rui Liu, Li-Min Mu, Jing Bai, Ya-Fei Du, Ying Xie and Wan-Liang Lu iD *
}

Triple negative breast cancer (TNBC) has been characterized as a very heterogeneous subtype, and is more invasive and non-expressing of the genes for the estrogen receptor (ER), progesterone receptor (PR) and HER2/neu, with poor prognosis, and hence the efficacy of regular chemotherapy is very limited. Here, we report a kind of double strand RNA (dsRNA) mPEI nanoparticle for treatment of invasive TNBC. The studies were performed on TNBC cells in vitro and in TNBC cancer-bearing mice. The results showed that dsRNA mPEI nanoparticles were able to effectively transfect cells, and demonstrated a strong capability in knocking-down the Fra-1 gene and down-stream MMP-1 and MMP-9 genes in TNBC cells and TNBC cancer-bearing mice, thereby inhibiting the invasion and migration of cells. After intratumoral injection, dsRNA mPEI nanoparticles exhibited a robust anticancer efficacy in TNBC cancer-bearing mice, and the anticancer efficacy was superior to that of paclitaxel. In conclusion, dsRNA mPEI nanoparticles are able to effectively treat aggressive TNBC, and the mechanism studies reveal that they take effect by knocking-down Fra-1 relevant genes, hence interfering in transcription and translation of the genes, which are necessary for growth and metastasis of TNBC. Therefore, the present study offers a new and promising formulation and strategy for effective treatment of TNBC.

\section{Introduction}

Triple negative breast cancer (TNBC) has been characterized as the breast cancer that does not express the genes for the estrogen receptor (ER), progesterone receptor (PR) and HER2/ neu. ${ }^{1}$ This makes TNBC more difficult to treat ${ }^{2}$ because most hormone therapies target one of the three receptors, therefore TNBC often requires a combinational treatment. Moreover, TNBC comprises a very heterogeneous subtype; some types of triple-negative breast cancer are more aggressive, with poor prognosis, although other types have very similar treatment outcomes to hormone receptor positive breast cancers. ${ }^{3}$ The standard therapeutic strategies for TNBC are surgery with adjuvant/neoadjuvant chemotherapy and radiotherapy. However, TNBC is generally very susceptible to chemotherapy. In some cases, early complete response does not correlate with overall survival. This makes it particularly complicated to treat TNBC. ${ }^{4}$

Herein, we hypothesized that the dsRNA mPEI nanoparticles could treat the aggressive triple negative breast cancer by

State Key Laboratory of Natural and Biomimetic Drugs, Beijing Key Laboratory of Molecular Pharmaceutics and New Drug System, School of Pharmaceutical Sciences, Peking University, Beijing 100191, China. E-mail: luwl@bjmu.edu.cn; Fax: +86 10 82802683; Tel: +861082802683

† Electronic supplementary information (ESI) available. See DOI: 10.1039/c9ra01889a inhibiting invasive target genes. In this study, double strand RNA (dsRNA) is used as a stable structure to be encapsulated into $\mathrm{mPEI}$ nanoparticles for silencing the aggressive genes of TNBC while mPEI is a newly synthesized safe cationic polymer material for delivery of dsRNA into TNBC cells.

dsRNA is a double strand RNA designed based on endogenous microRNA. Its sense strand is identical to the strand of microRNA, and the anti-sense strand is complementary to the sense strand. As an evolutionarily conserved class of small noncoding RNAs (of 18-24 nucleotides), ${ }^{5}$ microRNAs (miRNAs) have emerged as pivotal regulators of gene expression ${ }^{6}$ and are involved in a variety of cellular processes, including differentiation, growth control, and cell fate determination. ${ }^{7}$ miRNAs often negatively regulate gene expression at the posttranscriptional level, with each miRNA able to target several mRNA species. ${ }^{8}$ miRNAs function through the argonaute (AGO) proteins, ${ }^{9}$ which usually exist in a RNA-induced silencing complex (RISC) that contains both RNA binding domains and RNase $\mathrm{H}$ domains. ${ }^{10}$ As a kind of miRNA, miR-34a is recognized as a master regulator of tumor suppression. ${ }^{\mathbf{1 1}}$ Similarly to the biogenesis of all miRNAs, miR-34a is transcribed as a long hairpin molecule (pri-miRNA), which is subsequently cleaved by an RNase III Drosha to an approximately 70-nucleotide long stem-loop precursor (pre-miRNA). ${ }^{12}$ Following nuclear export, the pre-miRNA is further cleaved by an RNase III Dicer into 22nucleotide long mature strands, which are incorporated into RNA-induced silencing complex (RISC). ${ }^{13}$ This RNA/protein 
A<smiles>CCCNCCN(CCNCCN(CCN)CCN)CCN(CCNC(C)(C)N)CCN(CCN)CCN</smiles>

B

.
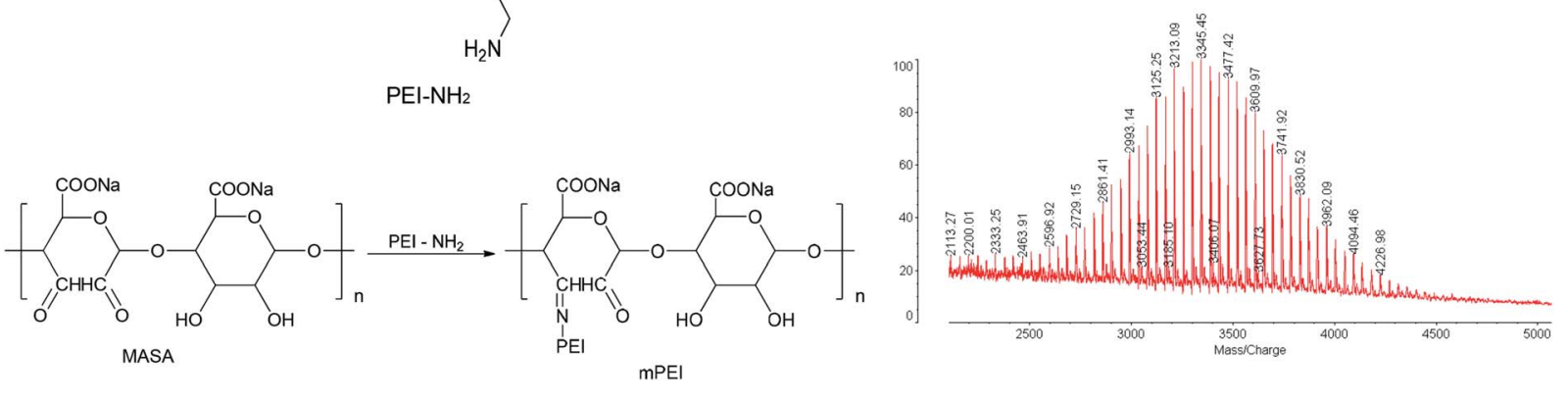

Fig. 1 Synthesis and identification of functional mPEI material. (A) Synthetic route of functional mPEI material. The multiple aldehyde sodium alginate was reacted with $\mathrm{NaIO}_{4}$ by oxidation to form MASA, which was then reacted with $\mathrm{PEI}$ by aldehyde-amine condensation to form mPEI. (B) MALDI-TOF-MS spectra of MASA. Molecular weight of MASA was 1745.75. (C) MALDI-TOF-MS spectra of mPEI. Molecular weight of mPEI was 3345.45. The molecular weight of PEI used in the experiment was 1600 . The results demonstrate that the synthesis of functional material is successful. Abbreviations: SA, sodium alginate; MASA, multiple aldehyde sodium alginate; PEI, polyethyleneimine; mPEI, conjugate of MASA with PEI.

complex mediates down-regulation of target transcripts by mRNA degradation or inhibition of translation. ${ }^{\mathbf{1 4 , 1 5}}$

As one member of the activator protein-1 (AP-1) family, ${ }^{16}$ FOS-related antigen 1 (FRA-1), ${ }^{17}$ is located on chromosome $11 \mathrm{q} 13$ and encodes a mature mRNA of $1.7 \mathrm{~kb}$ in length. It is emerging as a key regulator of invasion in cancer cells and overexpressed in several types of human cancers. ${ }^{18}$ Fra-1 regulates several genes, implicates in invasion, angiogenesis and cell proliferation ${ }^{\mathbf{1 9 , 2 0}}$ and directly induces the promoter activity of matrix metalloproteinase (MMP-1 (ref. 21) or MMP-9). ${ }^{22}$ MMP family is a family of metalloproteinase-dependent proteolytic enzymes that can effectively degrade extracellular matrices and play an important role in tumor growth and metastasis. ${ }^{23}$ Tumor cells must penetrate the basement membrane and traverse the extracellular matrix in order to invade surrounding structures and metastasize to distant sites. ${ }^{24,25}$

Polyethylenimine (PEI) has been widely used as a polycationic material for loading miRNAs. ${ }^{26}$ It is divided into two types: linear and branched. ${ }^{27}$ Branched PEI has a large specific surface area and a large positive charge on the surface. It can highly compress nucleic acids to form complexes, which can be integrated into cells by fusion with negatively charged cell membranes. ${ }^{28}$ Although PEI has high transfection efficiency due to positive electricity, the resulting strong cytotoxicity is not negligible. Therefore, a number of studies focused on the modification of PEI to reduce cytotoxicity and increase miRNA uptake into the cell at the same time. ${ }^{29}$ Sodium alginate is a byproduct of the extraction of iodine and mannitol from kelp or sargasso of brown algae. The molecule is linked by $\beta$-D-mannuronic acid and $\alpha$-L-guluronic acid by $1-4$ bonds. It is a natural polysaccharide with the stability and safety required for pharmaceutical preparations.

The objectives of the present study were to develop a stable dsRNA nanoparticle, confirm its function for treating the aggressive triple negative breast cancer, and reveal the relevant mechanism. In the study, we synthesized multiple aldehyde sodium alginate-polyethyleneimine (MPEI) nanoparticles to carry double strand microRNA (dsRNA). The dsRNA mPEI nanoparticles could increase dsRNA uptake into the triple negative breast cancer (TNBC) cells, provide lysosomal escape ability and enhance the knockdown effect on the target genes of the cancer cells in vitro and in vivo.

\section{Results and discussion}

\subsection{Synthesis and characterization of MASA and mPEI materials}

To produce the reactive aldehyde group, multiple aldehyde sodium alginate (MASA) was firstly produced by oxidizing sodium alginate with sodium periodate under stirring at 

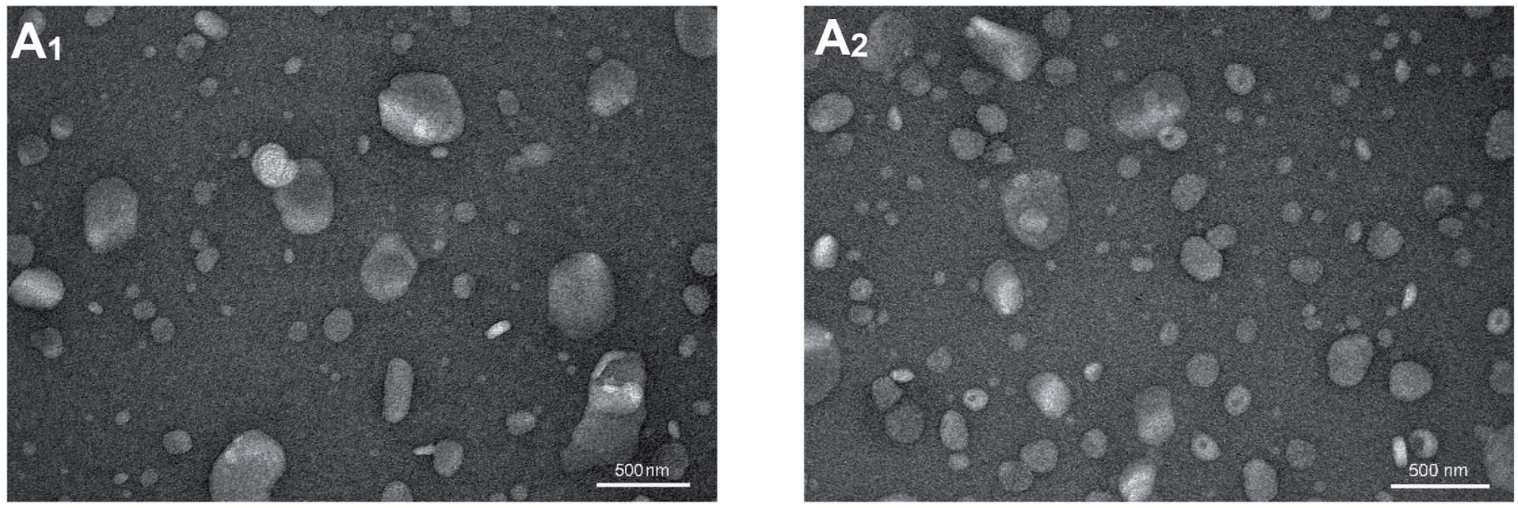

B

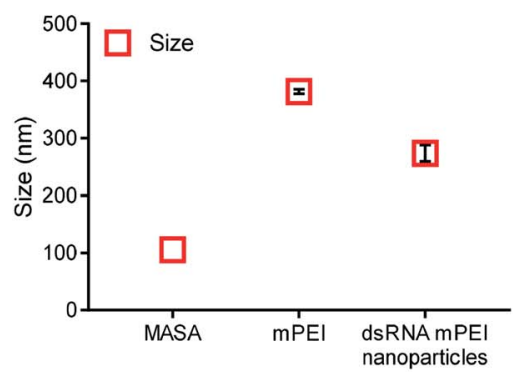

C

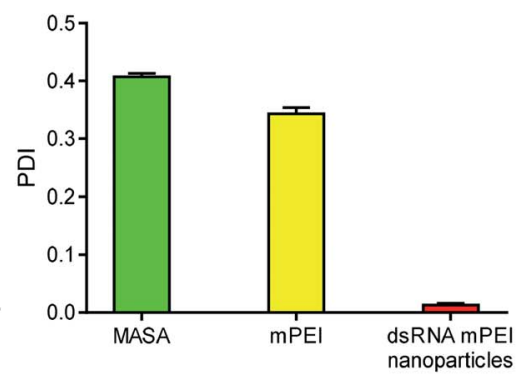

D

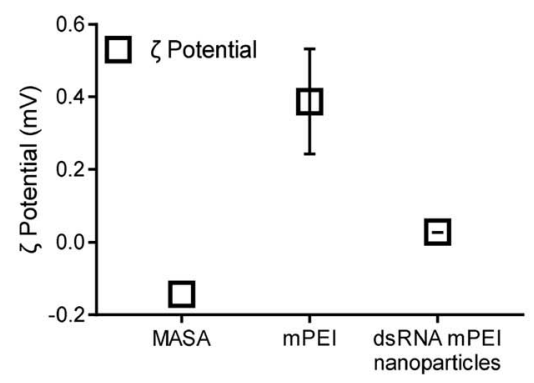

E

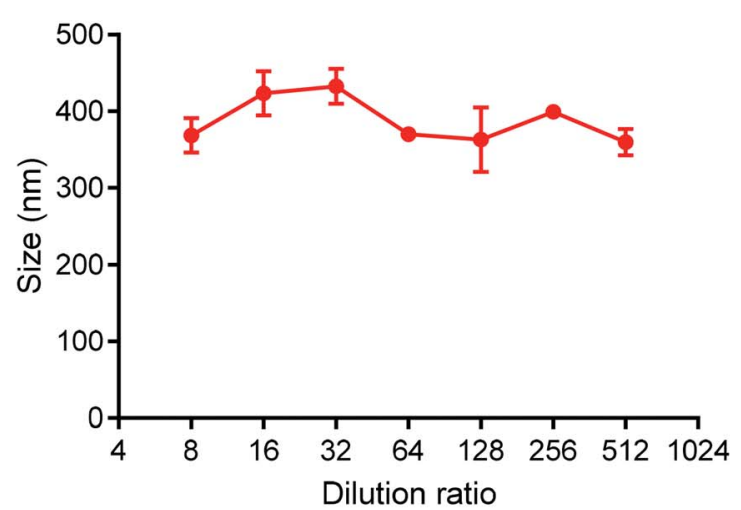

F

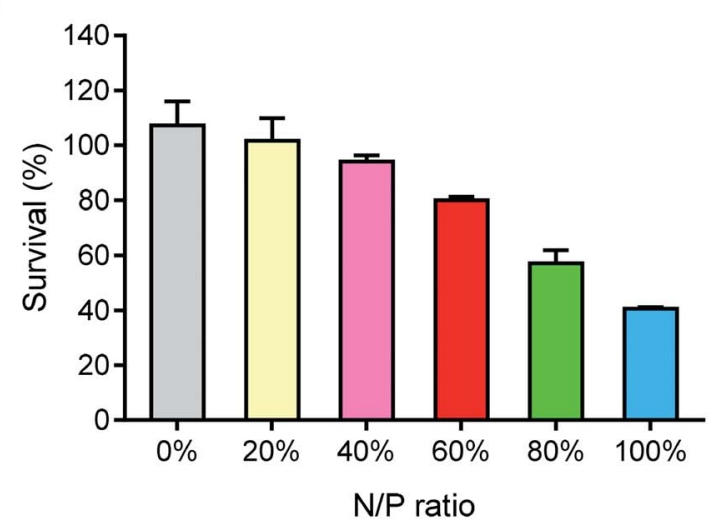

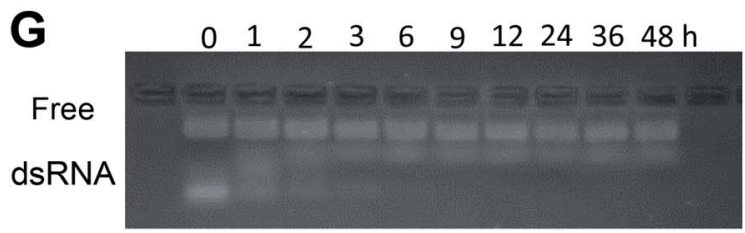

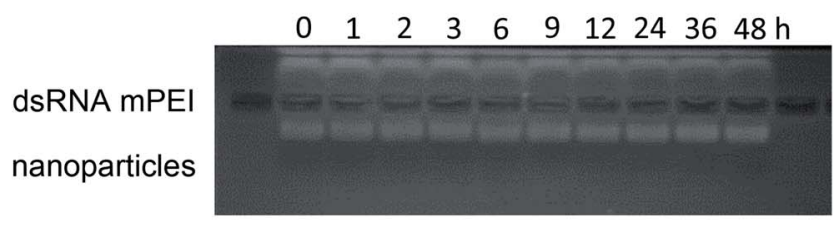

Fig. 2 Characterization of dsRNA mPEI nanoparticles. (A) TEM images of mPEI $\left(A_{1}\right)$ and dsRNA mPEl nanoparticles $\left(A_{2}\right)$ in cell culture medium. The results demonstrate that the average diameter of mPEI and dsRNA mPEI nanoparticles are about $350 \mathrm{~nm}$ and $200 \mathrm{~nm}$, respectively. (B) Sizes of MASA, mPEI and dsRNA mPEI nanoparticles measured by DLS. The particle sizes of MASA, mPEl and dsRNA mPEI nanoparticles were $105.5 \pm$ $17.05,381.6 \pm 3.81$, and $273.7 \pm 14.41 \mathrm{~nm}$, respectively. (C) PDIs of MASA, mPEl and dsRNA mPEI nanoparticles measured by DLS. The PDIs of MASA, mPEl and dsRNA mPEI nanoparticles were $0.407 \pm 0.006,0.343 \pm 0.011$ and $0.013 \pm 0.003$, respectively. The results demonstrate that the distributions of the particle size are of uniform. (D) Zeta potentials of MASA, mPEI and dsRNA mPEI nanoparticles measured by DLS. The results demonstrate that MASA is negatively charged while after reaction with PEI, the resultant $\mathrm{MPEl}$ is positively charged. (E) The dilution stability of dsRNA mPEI nanoparticles in cell culture medium. The results demonstrate that the dilution by culture medium doesn't affect the sizes of dsRNA $\mathrm{mPEI}$ nanoparticles. (F) In vitro cytotoxicity of different N/P ratios of dsRNA mPEI nanoparticles in human breast cancer MDA-MB-231 cells. A N/P ratio at $60 \%$ of dsRNA mPEI nanoparticles was selected for further experiments to guarantee a high transfection efficiency but a lower cytotoxicity to cancer cells. (G) The serum stability of free dsRNA and dsRNA mPEl nanoparticles by gel retardation assay in $48 \mathrm{~h}$. The results demostrate that the dsRNA mPEI nanoparticles can effectively prevent dsRNA degradation in serum. Data are presented as the mean \pm standard deviation $(n=3$ ). Abbreviations: TEM, transmission electron microscopy; DEPC, diethyl pyrocarbonate; MASA, multiple aldehyde sodium alginate; PEI, polyethyleneimine; mPEI, conjugate of MASA with PEI; dsRNA, double strand microRNA; DLS, dynamic light scattering. 


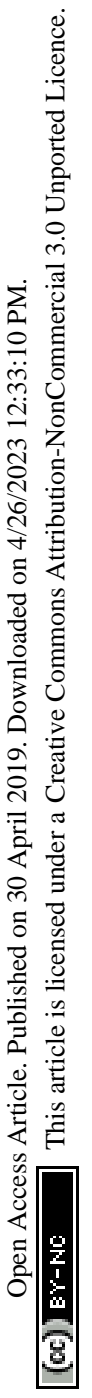

C
A 4T1

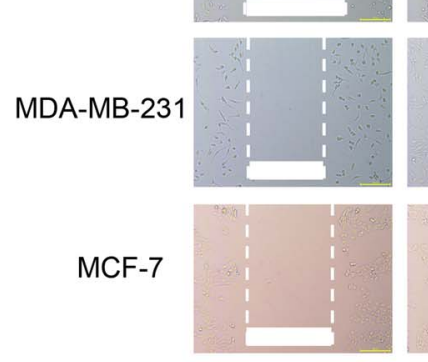
\begin{tabular}{l|l} 
& Day 0 \\
\hline & \\
1 & \\
1 &
\end{tabular} Day 1
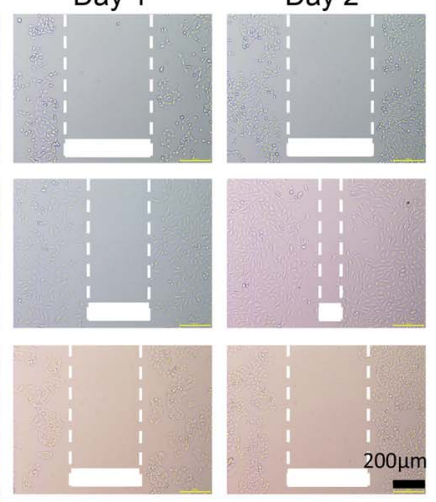

Day 2

B
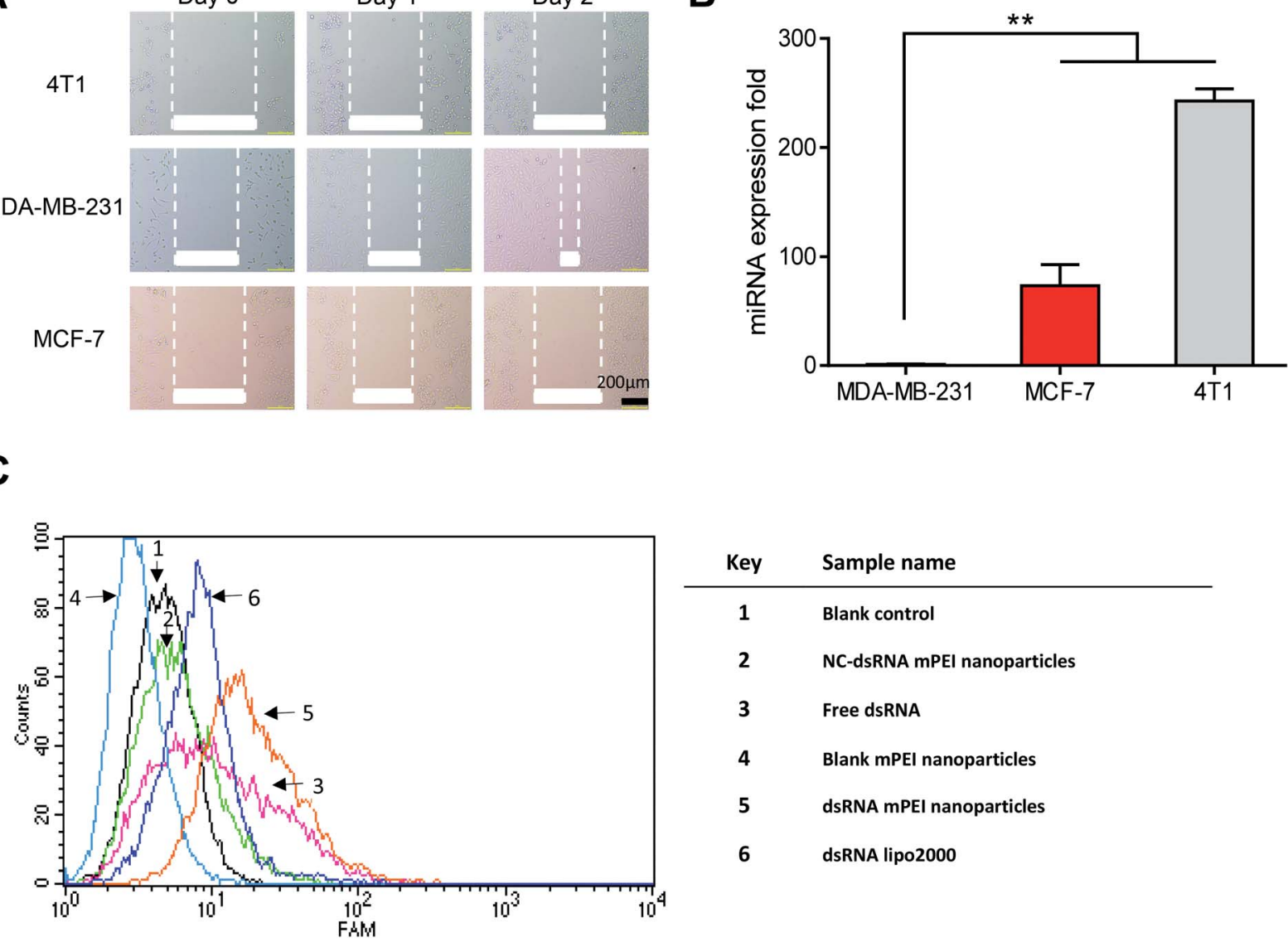

\begin{tabular}{cl} 
Key & Sample name \\
\hline 1 & Blank control \\
2 & NC-dsRNA mPEI nanoparticles \\
3 & Free dsRNA \\
4 & Blank mPEI nanoparticles \\
5 & dsRNA mPEI nanoparticles \\
6 & dsRNA lipo2000
\end{tabular}

D

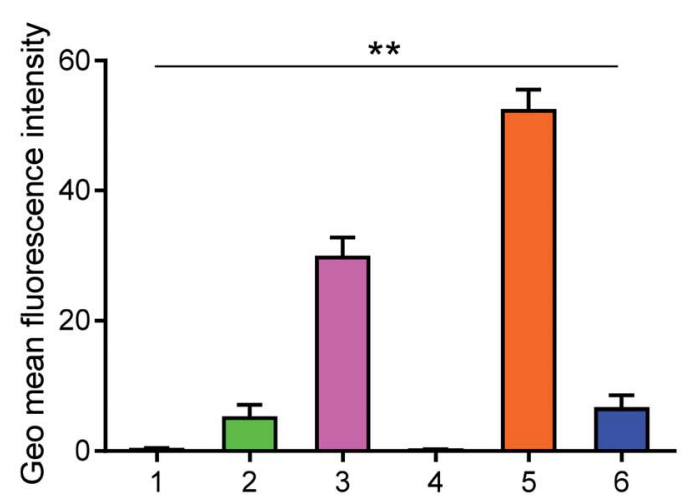

E
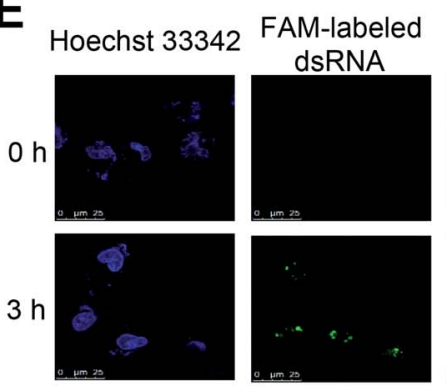

FAM-labeled
dsRNA
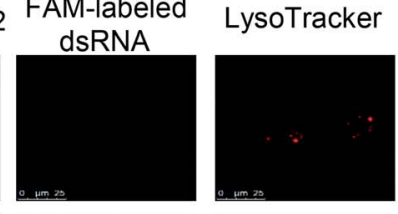

Merged

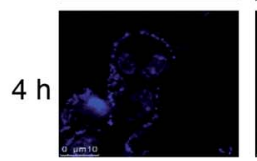

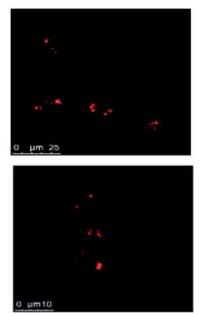

Fig. 3 Expression of target miRNA-34a and cellular uptake of dsRNA mPEl nanoparticles in various breast cancer cells. (A) Comparison of invasiveness for mouse breast cancer 4T1, human TNBC MDA-MB-231 cells and human breast cancer MCF-7 cells by scratch assay. The results demonstrate that the MDA-MB-231 cells are more invasive as compared with MCF-7 or 4T1 cells. The scale bar is $200 \mu \mathrm{m}$. (B) Expression levels of target miRNA-34a in MDA-MB-231, MCF-7, and 4T1 cells measured by qRT-PCR. The results demonstrate that the expression of target miRNA$34 a$ in MDA-MB-231 cells is significantly lower than that in MCF-7 or 4T1 cells. Data are presented as the mean \pm standard deviation ( $n=4), P<$ 0.05. (C) Cellular uptake of dsRNA mPEI nanoparticles by MDA-MB-231 cells measured by flow cytometry. The results from FAM labeled fluorescence demonstrate that the dsRNA mPEI nanoparticles are the most internalized by the cancer cells as compared with free dsRNA or dsRNA lipo2000. (D) Qualitative analysis for the cellular uptake of dsRNA mPEl nanoparticles by MDA-MB-231 cells measured by flow cytometry. (1) Blank control; (2) NC-dsRNA mPEI nanoparticles; (3) free dsRNA; (4) blank mPEI nanoparticles; (5) dsRNA mPEI nanoparticles; (6) dsRNA lipo2000. Data are presented as the mean \pm standard deviation $(n=3), P<0.05$. (E) The endosomal escape assay of dsRNA mPEI nanoparticles in MDA-MB-231 cells. The assay were detected by confocal microscopy after $0 \mathrm{~h}, 3 \mathrm{~h}$, and $4 \mathrm{~h}$ incubation of dsRNA mPEI nanoparticles (FAMlabeled dsRNA, green). The nucleus and lysosomes were respectively stained by Hoechst 33342 (blue) and LysoTracker (red). At 3 h, dsRNA mPEI nanoparticles were enraptured by lysosomes. Yellow was the merged color of FAM-labeled dsRNA (green) and LysoTracker (red), indicating the co-localization of dsRNA mPEI nanoparticles with the lysosomes. At $4 \mathrm{~h}$, dsRNA mPEI nanoparticles escaped from the lysosomes, and the lysosomal escape was indicated by the separation of red and green color. Abbreviations: miRNA, microRNA; dsRNA, double strand microRNA. 
ambient temperature (Fig. 1A). The resultant powders were confirmed by MALDI-TOF-MS spectrum (Fig. 1B). It could be seen that the average mass of the product was $\mathrm{m} / \mathrm{z} 1745.45$.

To synthesize mPEI, MASA was connected with PEI using aldehyde-amine condensation in a slightly alkaline environment (Fig. 1A). The obtained products were also confirmed by MALDI-TOF-MS spectrum (Fig. 1C). The results demonstrated that the average mass of the product was $m / z 3345.45$ and the mass distribution was concentrated.

By comparing the mass of the two products, the results showed that the difference of the average mass between the two was equal to that of PEI $(\mathrm{m} / \mathrm{z} 1600)$, thus indicating a successful synthesis of mPEI by linking MASA with PEI. And mPEI was used as a gene carrier in subsequent experiments.

\subsection{Preparation and characterization of dsRNA MPEI nanoparticles}

dsRNA and mPEI materials were able to self-assemble to nanoparticles by static attraction in the liquid state. When dsRNA was added into mPEI, dsRNA could be encapsulated into mPEI to form dsRNA mPEI nanoparticles.

To characterize dsRNA mPEI nanoparticles, the morphologies of mPEI vector and dsRNA MPEI nanoparticles were observed by transmission electron microscopy (TEM). The

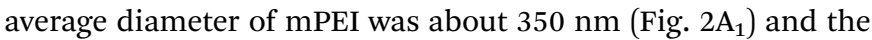
average diameter of dsRNA mPEI nanoparticles was about $200 \mathrm{~nm}$ (Fig. 2A ). The results demonstrated that mPEI and dsRNA mPEI nanoparticles were both round in shape, and there were no obvious aggregations. Because the positive and negative charges interacted with each other to form nanoparticles, the size of dsRNA mPEI nanoparticle was smaller than mPEI.

Sizes and zeta potentials were further analyzed by dynamic light scattering (DLS). The particle sizes of MASA, mPEI and dsRNA mPEI nanoparticles were $105.5 \pm 17.0,381.6 \pm 3.8$, and $273.7 \pm 14.4 \mathrm{~nm}$, respectively (Fig. 2B). And the PDIs of MASA, mPEI and dsRNA mPEI nanoparticles were $0.407 \pm 0.006,0.343$ \pm 0.011 and $0.013 \pm 0.003$, respectively (Fig. 2C). When the positively charged mPEI bound to the negatively charged dsRNA, the particle size was slightly reduced due to electrostatic interaction. The sizes determined by TEM were smaller than that seen in DLS experiments, which might be due to dehydration effects that occurred during TEM sample preparation, leading to shrinking of the nanoparticles. The dilution stability results showed that the particle size was stable within a small range after dilution of different ratios (Fig. 2E). Since nanoparticles can be diluted up to 100 times by blood after entering the circulation of the body, a certain anti-dilution stability is necessary to ensure more accumulation of nanoparticles in the lesions and to exert effects.

After combined with negative dsRNA, dsRNA MPEI nanoparticles exhibited slightly positively charged $(0.03 \pm 0.00 \mathrm{mV})$ (Fig. 2D), showing a decrease in the electropositivity as compared to $\mathrm{MPEI}(0.39 \pm 0.14 \mathrm{mV})$. The slight electropositivity may benefit for lowering the potential cytotoxicity of delivery material itself, and for cellular uptake by cancer cells due to a negatively charged cell membrane. It is characterized that PEI is often associated with significant cytotoxic effects. ${ }^{30}$ Therefore, it is necessary to evaluate the cell viability of nanoparticles when used as dsRNA delivery carriers. SRB staining assay was used to evaluate the safety of dsRNA mPEI nanoparticles at different N/ $\mathrm{P}$ ratios (Fig. 2F). When the N/P ratios were set as a range of $0 \%$ (dsRNA only, dsRNA control)-100\% (mPEI nanoparticles only, mPEI control), the cytotoxicity in MDA-MB-231 cells at $48 \mathrm{~h}$ incubation gradually increased. The results showed that the dsRNA mPEI nanoparticles at $60 \% \mathrm{~N} / \mathrm{P}$ ratio had an acceptable cytotoxicity ( $>80 \%$ viability of cells) and were suitable for further experimental evaluations. Accordingly, the $\mathrm{N} / \mathrm{P}$ ratio at $60 \%$ was selected for preparing dsRNA mPEI nanoparticles and used in the following evaluations due to the safety concern of nanoparticle materials. ${ }^{31}$

To evaluate the stability of dsRNA mPEI nanoparticles in blood, the protective effects of MPEI nanoparticles on dsRNA were analyzed by the gel retardation assay (Fig. 2G). It could be seen that free dsRNA would be degraded within $6 \mathrm{~h}$. In contrast, intact dsRNA could be seen in the band of image for dsRNA mPEI nanoparticles at $48 \mathrm{~h}$, demonstrated that the dsRNA mPEI nanoparticles could protect dsRNA from RNase degradation in serum and had a potential for future drug administration. There exist RNA degradation enzymes in physiological environment and cytoplasm of cancer cells, the protective effect of mPEI nanoparticles enables dsRNA to be less degraded during drug administration.

\subsection{Invasiveness characterization of breast cancer cells}

To characterize the invasiveness of different breast cancer cells, human TNBC MDA-MB-231 cells, human breast cancer MCF-7 cells and mouse breast cancer $4 \mathrm{~T} 1$ cells were included for illustrating the invasiveness by using wound-healing assay and qRT-PCR assay.

It could be seen that, after two days of incubation, the wounds in MDA-MB-231 cells were clearly healed, while the wounds in MCF-7 and 4T1 cells did not change obviously (Fig. 3A). The results from the wound-healing assay indicated that the MDA-MB-231 cells had the strongest invasiveness among the three breast cancer cells. Furthermore, the results from evaluation on miRNA expression by qRT-PCR showed that the miR-34a expression in MDA-MB-231 cells was the lowest among the three cells (Fig. 3B). As miR-34a, an intrinsic miRNA in the cells, has been associated with the inhibition of the invasiveness of the cancer, ${ }^{32,33}$ the result further indicated that the MDA-MB-231 cells were the strong invasive cancer cells, and accordingly, selected for further experimental evaluations in the present study.

\subsection{Cellular uptake and lysosomal escape in TNBC cells}

High cellular uptake of dsRNA is an initial step for gene transfection and for gene therapy effects. ${ }^{34}$ To evaluate the cellular uptake effect of dsRNA mPEI nanoparticles, FAM-labeled dsRNA was used as a fluorescence indicator to detect the intracellular fluorescence intensity by flow cytometry. The results showed that the dsRNA mPEI nanoparticles had the highest fluorescence intensity among varying control 
A

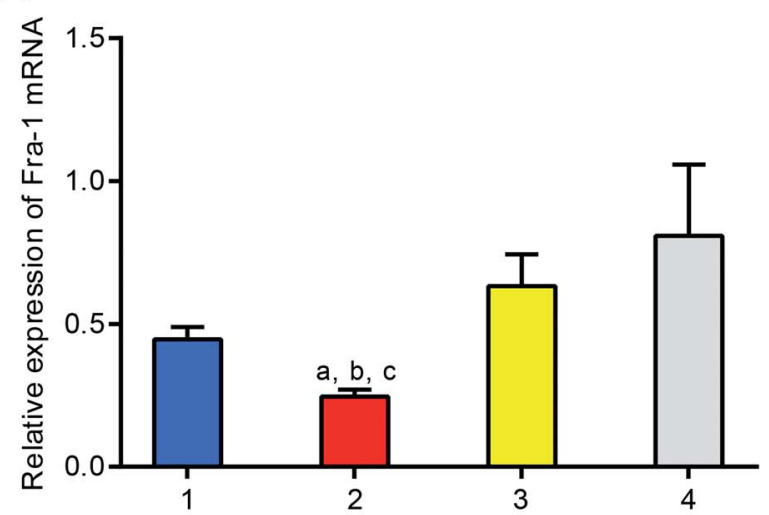

C

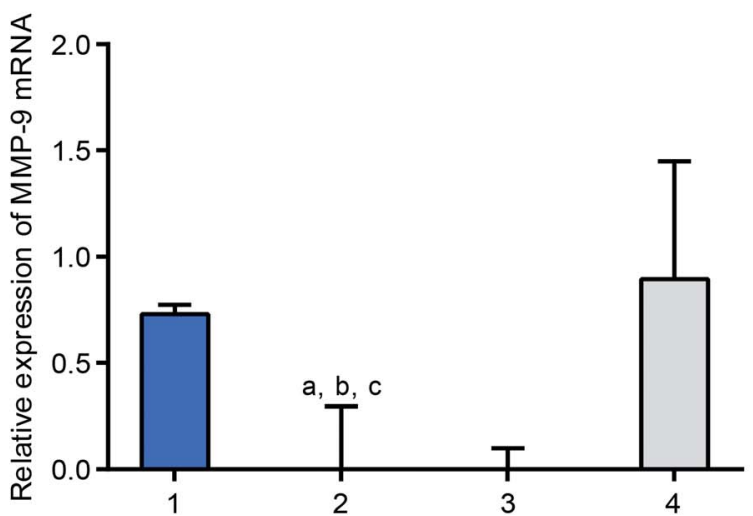

B

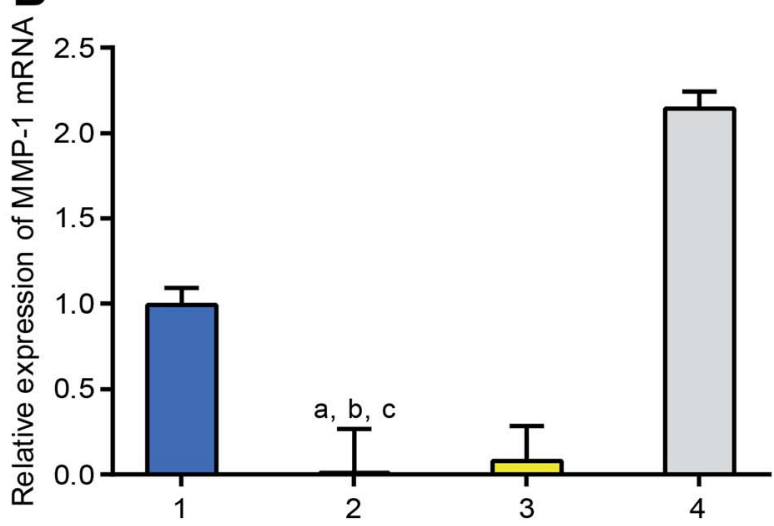

D

$\beta$-actin

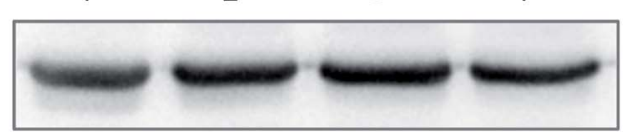

Fra-1

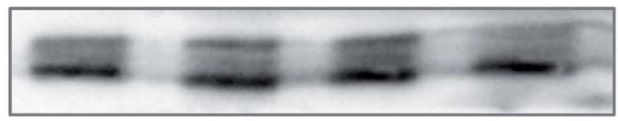

MMP-1

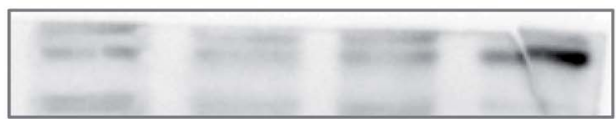

MMP-9

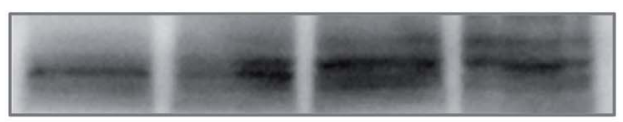

Fig. 4 Inhibitory effect on the Fra-1 relevant genes of dsRNA mPEl nanoparticles in TNBC cells in vitro. (A) dsRNA mPEI nanoparticles knockingdown mRNA of Fra-1 in human TNBC MDA-MB-231 cells in vitro. (B) dsRNA mPEI nanoparticles knocking-down mRNA of MMP-1 in human TNBC MDA-MB-231 cells in vitro. (C) dsRNA mPEl nanoparticles knocking-down mRNA of MMP-9 in human TNBC MDA-MB-231 cells in vitro. (D) dsRNA mPEI nanoparticles down-regulating proteins of Fra-1, MMP-1, and MMP-9 in human TNBC MDA-MB-231 cells in vitro. The results demonstrate that the protein of MMP-1 is evidently lowered by dsRNA mPEl nanoparticles in vitro while those of Fra-1 and MMP-1 are slightly lowered. (1) NC-dsRNA mPEI nanoparticles; (2) dsRNA mPEI nanoparticles; (3) dsRNA lipo2000; (4) ssRNA mPEI nanoparticles, an inhibitor of dsRNA. (A-C) The study was performed by qRT-PCR; (D) the study was performed by western blotting assay. Data are presented as the mean \pm standard deviation ( $n=4$ ), P<0.05. (a) vs. 1; (b) vs. 3; (c) vs. 4. Abbreviations: dsRNA, double strand microRNA; PEl, polyethyleneimine; mPEI, conjugate of multiple aldehyde sodium alginate (MASA) with PEI; TNBC, triple negative breast cancer.

formulations at $4 \mathrm{~h}$ incubation with MDA-MB-231 cells, indicating that dsRNA MPEI nanoparticles were the most significantly internalized by the cells (Fig. 3C). As a quantitatively estimation by flow cytometry, the cellular uptake of dsRNA mPEI nanoparticles was 8-folds higher than that of dsRNA lipo2000 (Fig. 3D), demonstrating a very strong cellular uptake and transfection efficiency of dsRNA into breast cancer cells.

The different cellular uptake effects of the varying formulations can be explained by the following aspects. In the image (Fig. 3D), the sample 1 is used as a blank control, and accordingly, there is no fluorescent signal detected for the cellular uptake; the sample 2 is used as a negative control, in which a meaningless dsRNA (negative effect) is labeled with FAM and encapsulated in mPEI nanoparticles. Since the meaningless dsRNA enters cells and can't be bound to the target mRNAs, it is cleared by the cells. Therefore, the fluorescent signal is less detected; the sample 3 is used as an isotype control, free dsRNA is degraded by nucleases after entering cells, hence weakening the fluorescent signal; the sample 4 is used as a compensation control, which doesn't contain FAM and therefore has no fluorescent signal, and is used to eliminate interference from impurities. In contrast, the sample 5 is used as a test sample, and the sample 6 is used as positive control. In comparison of sample 5 with sample 6 , the results indicate that the dsRNA delivery efficiency of mPEI nanoparticles is significantly higher than that of lipo2000 in MDA-MB-231 cells.

To investigate the lysosomal escape after cellular uptake, laser confocal microscopy was used to directly observe the escape of dsRNA mPEI nanoparticles in MDA-MB-231 cells after incubation at different time points. The blue, red and green fluorescent colors were used to indicate Hoechst 33342 labeled nuclei, LysoTracker labeled lysosomes, and FAM-labeled dsRNA, respectively. The yellow color was used to indicate the co-localization of FAM-labeled dsRNA (green) and LysoTracker (red). The results showed that the dsRNA mPEI nanoparticles were captured by lysosomes of MDA-MB-231 cells at $3 \mathrm{~h}$ incubation (Fig. 3E). In viewing the separation of red and green color at $4 \mathrm{~h}$ incubation, dsRNA mPEI nanoparticles already escaped 
A

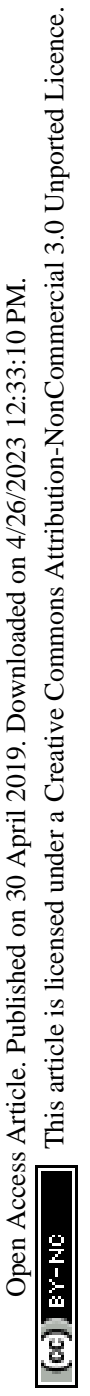
some escape.
A

Day 0

Day 1
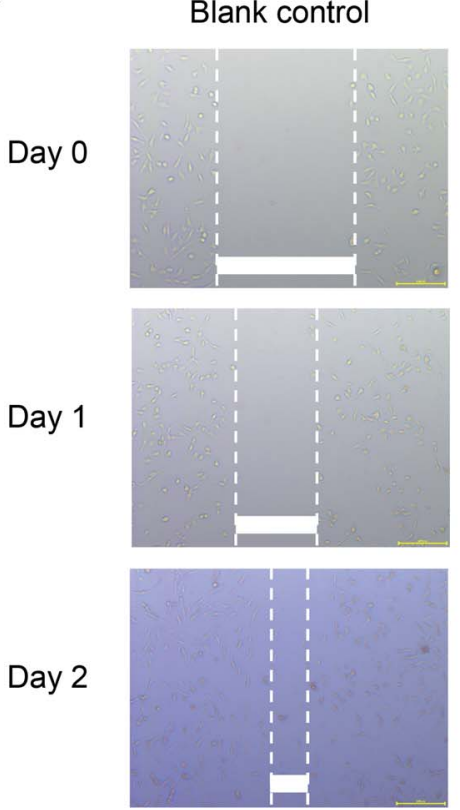

dsRNA mPEI nanoparticles
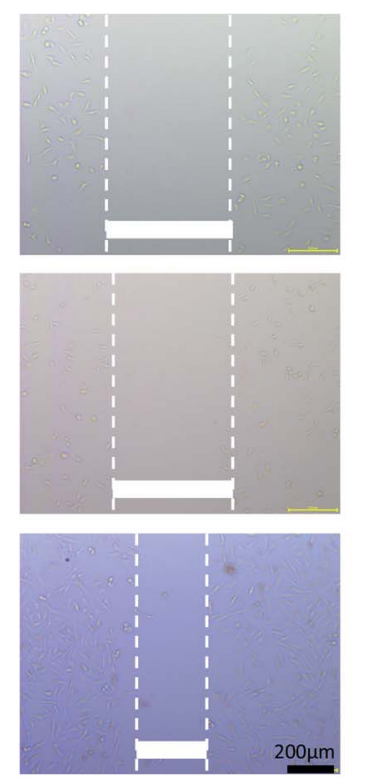

B

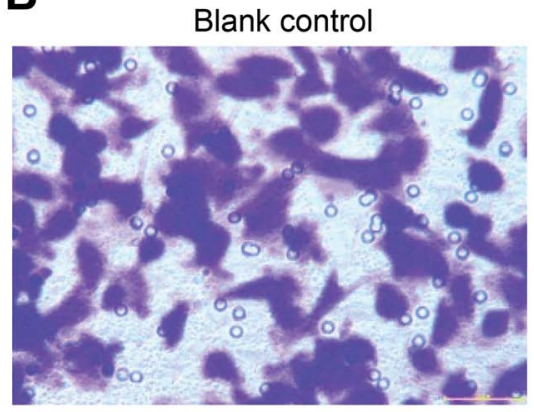

dsRNA mPEI nanoparticles

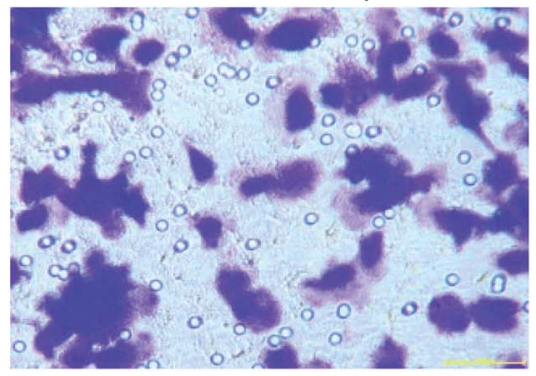

Fig. 5 Function verification of dsRNA mPEI nanoparticles in inhibiting the invasiveness of TNBC cells in vitro. (A) Migration inhibition of human TNBC MDA-MB-231 cells by dsRNA mPEI nanoparticles. The study was carried out by scratch assay. The results demonstrate that the dsRNA mPEI nanoparticles significantly reduce the migration ability of TNBC cells. The scale bar is $200 \mu \mathrm{m}$. (B) Invasiveness inhibition of human TNBC MDA-MB-231 cells by dsRNA mPEI nanoparticles. The study was carried out by transwell invasion assay. The results demonstrate that the dsRNA $\mathrm{mPEI}$ nanoparticles evidently reduce the invasion ability of TNBC cells. Abbreviations: dsRNA, double strand microRNA; mPEI, conjugate of multiple aldehyde sodium alginate (MASA) with PEI; TNBC, triple negative breast cancer.

from the lysosomes at this time point, indicating a rapid lyso-

The effective lysosomal escape of dsRNA mPEI nanoparticles can be explained by the proton sponge effect. ${ }^{35}$ In this process, the cationic nanoparticles are combined with the cell membrane, and enters the cells to form endosomes while the endosomes are fused with lysosomes, leading to the capture of dsRNA mPEI nanoparticles by lysosomes. In lysosomes, the unsaturated amino group on mPEI nanoparticles chelate with $\mathrm{H}^{+}$provided by the proton pump, leading to continuously open of the proton pump on membrane of lysosomes. Each proton causes a $\mathrm{Cl}^{-}$and a water molecule to remain in lysosomes, causing swelling and rupturing of the lysosomes. And then dsRNA mPEI nanoparticles are released into cytoplasm. During the process of lysosomal escape, dsRNA could be also released from the intact or the raptured nanoparticles to take effect.

\subsection{Knocking-down effect on the Fra-1 relevant genes in TNBC cells}

To study the knocking-down effect on mRNA in vitro, dsRNA mPEI nanoparticles were used to treat MDA-MB-231 cells, and the mRNAs of Fra-1, MMP-1 and MMP-9 in the cells were measured by qRT-PCR. The results showed that the dsRNA MPEI nanoparticles were significantly able to lower the mRNA levels of Fra-1 (Fig. 4A), MMP-1 (Fig. 4B) and MMP-9 (Fig. 4C). The knocking-down effect of dsRNA mPEI nanoparticles can be explained by the specific dsRNA, which is designed as a mimics sequence to supplement intrinsic miR-34a by which to inhibit the transcription of mRNA in cancer cells. ${ }^{36}$ Accordingly, extrinsic dsRNA bind with intrinsic mRNA, thereby interfering the transcription of mRNA. ${ }^{37}$

As a positive control, dsRNA lipo2000 also lowered the mRNA levels of Fra-1, MMP-1 and MMP-9 but had a smaller effect that of dsRNA mPEI nanoparticles. The results indicate that the transfection effect of MPEI nanoparticles are stronger than that of the commercially available transfection agent lipo2000. On the contrary, ssRNA mPEI nanoparticles, which are used as the inhibitor control, obviously increase the mRNA levels of Fra-1, MMP-1 and MMP-9. The inhibitory effect of ssRNA MPEI nanoparticles is due to the fact that the ssRNA is also specifically designed according to the sequence of intrinsic miR-34a, which is capable of blocking the action of miR-34a. As for the negative control, NC-dsRNA mPEI nanoparticles did not influence the mRNA level of MMP-1 mRNA but slightly reduced mRNA levels of Fra-1 and MMP-9. The reason could be explained that the meaningless RNA (referring to as NC-dsRNA) may bind with minor part of mRNAs as well, hence slightly interfering the transcription of mRNA.

To evaluate the knocking-down effect on the target proteins in vitro, dsRNA mPEI nanoparticles were used to treat MDA-MB231 cells, and the proteins of Fra-1, MMP-1 and MMP-9 in the cells were measured by western blotting (Fig. 4D). The results showed that both dsRNA mPEI nanoparticles and dsRNA lipo2000 were able to knock-down the protein expressions of Fra-1, MMP-1 and MMP-9. Among which, the protein expressions of MMP-1 and MMP-9 were more evident than that of Fra- 
A

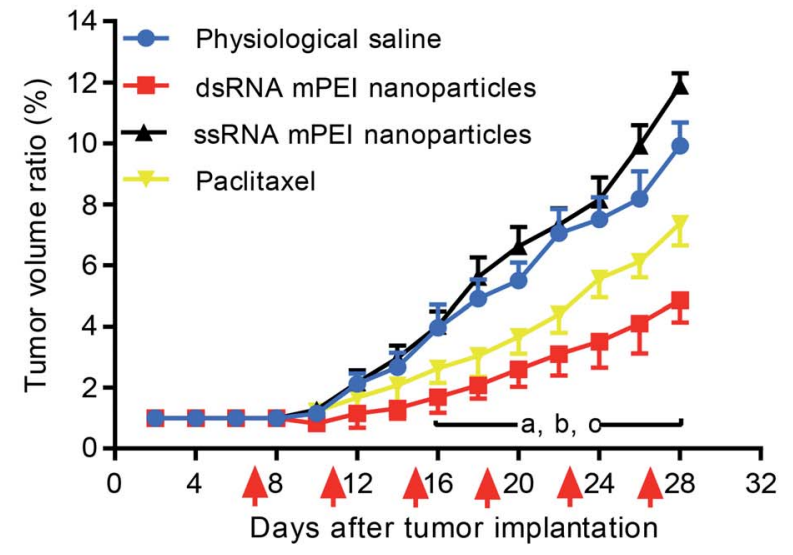

C

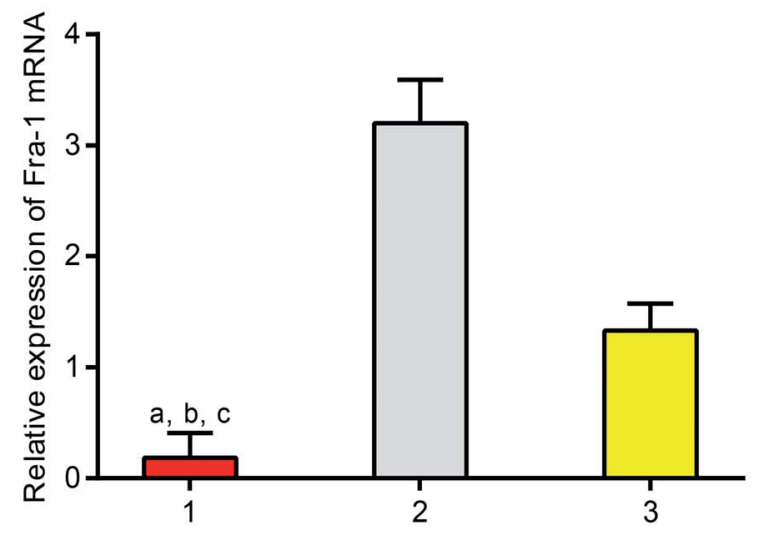

E

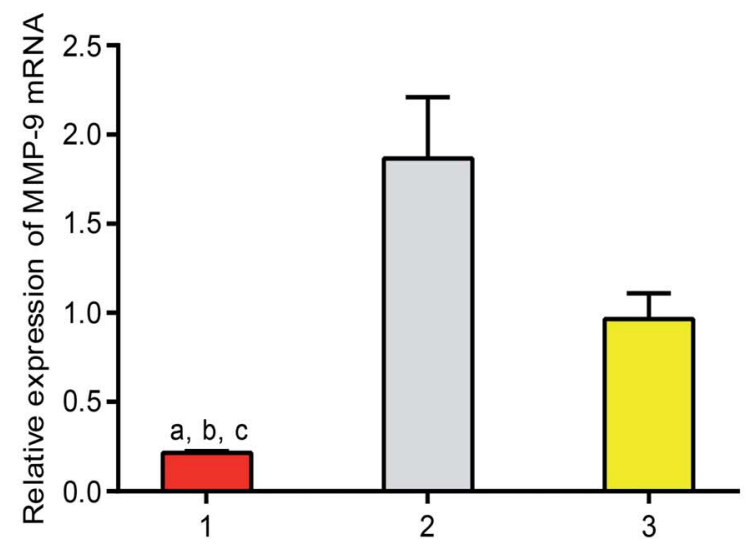

B

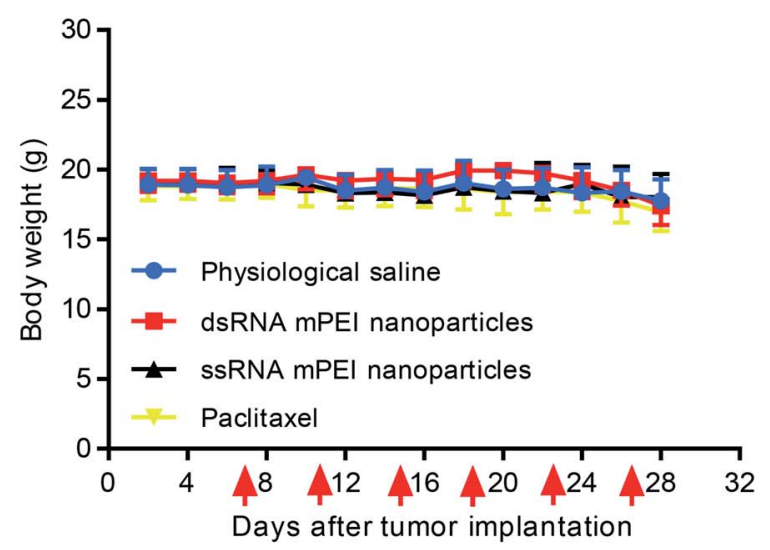

D

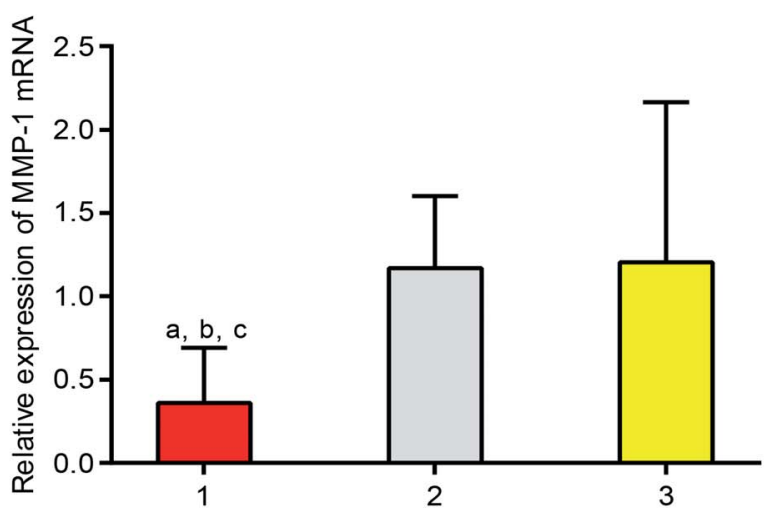

F

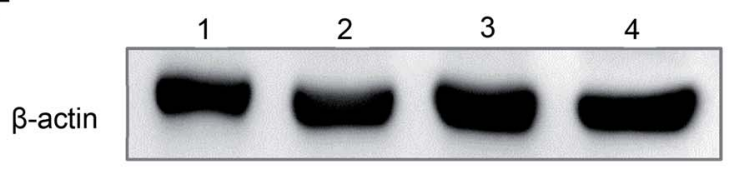

Fra-1

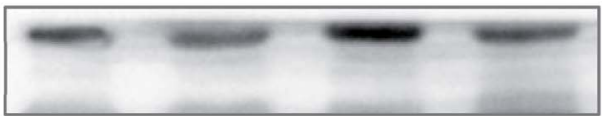

MMP-1

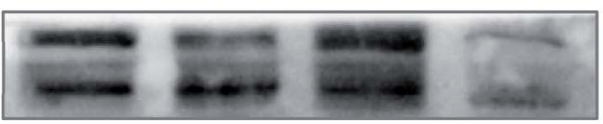

MMP-9

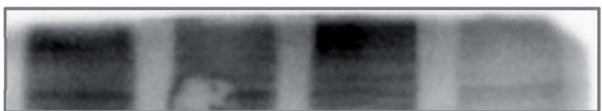

Fig. 6 Antitumor efficacy and inhibitory effect on the Fra-1 relevant genes in TNBC cancer-bearing mice. (A) Antitumor effect of dsRNA mPEI nanoparticles in TNBC MDA-MB-231 cells xenografted nude mice. The results demonstrate that the dsRNA mPEI nanoparticles significantly inhibit tumor proliferation in TNBC cancer-bearing mice. The red arrow indicates the day of drug administration. $P<0.05$, (a) vs. physiological saline; (b) vs. ssRNA mPEI nanoparticles; (c) vs. paclitaxel. (B) Body weight of mice after treatment with varying formulations. The results indicates the preliminary safety after administrations of dsRNA mPEI nanoparticles. (C) dsRNA mPEI nanoparticles knocking-down mRNA of Fra-1 in human TNBC cancer-bearing mice. (D) dsRNA mPEl nanoparticles knocking-down mRNA of MMP-1 in human TNBC cancer-bearing mice. (E) dsRNA mPEI nanoparticles knocking-down mRNA of MMP-9 in human TNBC cancer-bearing mice. (C-E) (1) dsRNA mPEI nanoparticles; (2) ssRNA mPEI nanoparticles, an inhibitor of dsRNA; (3) paclitaxel. (F) The study was performed by qRT-PCR. (F) dsRNA mPEI nanoparticles knocking-down proteins of Fra-1, MMP-1, and MMP-9 in human TNBC cancer-bearing mice. The results demonstrate that the proteins of Fra-1, MMP-1, and MMP-9 are lowered by dsRNA mPEI nanoparticles in vivo. The study was performed by western blotting assay. (1) Physiological saline; (2) dsRNA mPEI nanoparticles; (3) ssRNA mPEI nanoparticles (inhibitor); (4) paclitaxel. Data are presented as the mean \pm standard deviation $(n=6), P<0.05$. (a) vs. 2; (b) vs. 3. Abbreviations: dsRNA, double strand microRNA; PEl, polyethyleneimine; mPEl, conjugate of multiple aldehyde sodium alginate (MASA) with PEI; TNBC, triple negative breast cancer. 
1. This phenomenon could be explained by the regulation mechanism that the Fra-1 gene is an up-stream gene, which regulates the translation of down-stream genes (MMP-1 and MMP-9). Accordingly, the expressions of down-stream proteins (MMP-1, and MMP-9) are exhibited more significantly.

As an inhibitor control, ssRNA mPEI nanoparticles obviously increased the protein expressions of Fra-1, MMP-1 and MMP-9, demonstrating an evident inhibition to the knocking-down process. As a negative control, NC-dsRNA mPEI nanoparticles acted less effect these protein expressions.

The present design to knock-down Fra-1 and its relevant genes by dsRNA mPEI nanoparticles is based on the consideration that Fra-1 promotes the growth, invasion and metastasis of cancer cells. ${ }^{38}$ It is known that the intrinsic microRNA like miR-34 is able to inhibit the expression of Fra-1 gene in the normal cells. However, these intrinsic microRNAs are often insufficient to inhibit the higher expression of oncogenes (like Fra-1 gene) in the metastatic breast cancer and primary breast cancer with lymph node metastases. ${ }^{39}$ Accordingly, extrinsic supplement of active microRNA would assist to inhibit the growth and invasiveness of the cancer cells via knocking-down the oncogenes. The present study reveals that the dsRNA mPEI nanoparticles can reach such a purpose. In the design, dsRNA was synthesized according to the mimics of miR-34a, and mPEI nanoparticles could effectively deliver dsRNA into the TNBC cells to take effect.

As the downstream genes of Fra-1, MMP-1 and MMP-9 genes are closely associated with the migration and invasiveness of cancer, and exhibit over-expressions in the invasive breast cancer. $^{40,41}$ The results from the present study as indicated in below section demonstrate that the dsRNA mPEI nanoparticles can effectively down-regulate the expression of MMP-1 and MMP-9 genes as well, hence contributing to the inhibition to growth, invasion and migration of TNBC cells.

\subsection{Inhibition effect on the invasiveness of TNBC cells}

To investigate inhibitory effect on the invasiveness of cancer cells, dsRNA mPEI nanoparticles were used to treat TNBC MDAMB-231 cells, and the invasiveness was assessed by woundhealing assay and transwell invasion assay, respectively.

In the wound-healing assay, dsRNA mPEI nanoparticles significantly inhibited the wound-healing rate within two days as compared to blank control (Fig. 5A). As wound healing assay has been used to indicate cell migration and cell-cell interaction, ${ }^{42}$ it could be a straightforward observation for rapid growth rate and distant invasiveness of the malignant cancer cells. Therefore, the inhibition of wound-healing of MDA-MB-231 cells in the study could suggest that the dsRNA mPEI nanoparticles inhibit not only the invasiveness but also the growth of the cells.

The invasiveness of TNBC cells were further evaluated by transwell invasion assay, ${ }^{43}$ and the results showed that the dsRNA mPEI nanoparticles significantly inhibited the migration of MDA-MB-231 cells from the upper chamber to lower one (Fig. 5B). As the migration is able to more clearly indicate the motion and invasion of the malignant cells, the results from this study could reveal the inhibitory effect on the invasiveness of MDA-MB-231 cells, ${ }^{44}$ and consequently, the inhibitory effect on the invasiveness of TNBC cells verify the function of dsRNA mPEI nanoparticles from in vitro aspect.

A unique nanoparticle formulation could achieve the specific purposes in the diagnosis and/or therapy for the refractory TNBC cancer. For examples, it is reported that the cRGD, a cyclic arginine-glycine-aspartic acid (cRGD) modified nanoparticles, UCNP@TTD-cRGD NPs, ${ }^{45}$ cRGD-MEH-PPV NPs ${ }^{46}$ and cRGDsiVEGF-TTD NPs ${ }^{47}$ have been used for targeted diagnosis and therapy of TNBC cells. These nanoparticle formulations demonstrate remarkable potentials in the imaging by a targeting molecule mediation and in the photodynamic therapy (PDT) by generating ROS under light irradiation. ${ }^{48,49}$ In the present study, dsRNA mPEI nanoparticles are developed for gene therapy by inhibiting the growth, invasion and migration of TNBC cells through knocking-down Fra-1 and its relevant genes. Albeit the differences in the action mechanism and the components of nanoparticles, the results from the present study reveal a promising new nanoparticle formulation to inhibit the growth and to overcome the invasiveness of the TNBC cancer.

\subsection{Anticancer efficacy and inhibitory effect on Fra-1 relevant genes in TNBC cancer-bearing mice}

To evaluate the anticancer efficacy, MDA-MB-231 cells were inoculated into nude mice for establishing TNBC cancerbearing mice model. The results showed that the tumor volume reached $180-200 \mathrm{~mm}^{3}$ at day 7 since the inoculation of cancer cells, indicating a successful establishment of the model. After administrations, both physiological saline group and ssRNA mPEI nanoparticles (inhibitor) were not able to inhibit growth of the tumor. In contrast, dsRNA mPEI nanoparticles exhibited the stronger anticancer efficacy than paclitaxel in the TNBC cancer-bearing mice (Fig. 6A), demonstrating a robust inhibitory effect to growth of the TNBC tumor.

The result from in vivo anticancer efficacy indicate that the dsRNA mPEI nanoparticles have a strong cytotoxicity to TNBC cancer tissues. This result can successfully meet the expectation to inhibit the growth of TNBC cancer. However, it may also raise the safety concern that the dsRNA formulation may have a strong cytotoxicity to normal cells, tissues and organs. Actually, it may cause the cytotoxicity when the dsRNA formulation is given by a systemic administration, such as by intravenous injection. Nevertheless, the dsRNA formulation has little impact on the normal cells or tissues when it is given by topical administration via intra-tumoral injection. It is because the nanoparticles exhibit an enhanced permeability and retention (EPR) effect in tumor tissue over the range of 5-200 $\mathrm{nm}^{50}$ when administrated as an intravenous injection. In the case of intratumoral injection, bigger size $(>200 \mathrm{~nm})$ of the nanoparticles would be more beneficial for the "retention" effect, namely, nanoparticles could be accumulated into the tumor tissue.

After drug administration, the evaluation on body weight of mice could preliminarily indicate the safety of dsRNA mPEI nanoparticles. In this study, the changes of body weight were 
measured during the whole period of animal experiments (Fig. 6B). It could be seen that the body weights of tumorbearing mice were stable, indicating that the dsRNA mPEI nanoparticles could be safe when used in vivo.

To confirm the knocking-down effect on mRNA in vivo, tumor tissues were removed from nude mice, and the mRNAs of Fra-1, MMP-1 and MMP-9 were measured by qRT-PCR. The results showed that dsRNA mPEI nanoparticles could significantly lower the mRNA levels of Fra-1 (Fig. 6C), MMP-1 (Fig. 6D) and MMP-9 (Fig. 6E). On the contrary, ssRNA mPEI nanoparticles increased the mRNA levels of target genes. For paclitaxel group, expression levels of mRNA remained unchanged.

To study the knocking-down effect on the target proteins in vivo, the proteins of Fra-1, MMP-1 and MMP-9 were measured by western blotting assay. The results showed that dsRNA mPEI nanoparticles were able to knock-down the protein expressions of Fra-1, MMP-1 and MMP-9. As an inhibitor control, ssRNA mPEI nanoparticles increased protein expressions. For paclitaxel group, the protein expressions were not affected.

These results exhibited that the results in vivo were more significant than those in vitro, it might because the concentration of mRNA and protein extracted from tumor tissue was much higher than that extracted from cells. Therefore, the results obtained were more significant. Combining vitro and vivo results, it could be concluded that the dsRNA MPEI nanoparticles had a significant inhibitory effect on expression of Fra1, MMP-1 and MMP-9.

\section{Experimental section}

\subsection{Materials}

Sodium alginate, sodium periodate and ethylene glycol were purchased from J\&K Scientific Ltd. (Beijing, China). Polyethyleneimine solution was obtained from Sigma-Aldrich Co. (St. Louis, MO, USA). Opti-MEM reduced-serum medium was supplied by Life Technologies (Carlsbad, CA, USA). Lipofectamine 2000 was provided by Invitrogen (New York, NY, USA). Sulforhodamine B was purchased from Macklin Ltd. (Shanghai, China). dsRNA (sense strand: 5'-UGGCAGUGUCUUAGCUGGUUGU-3' ${ }^{\prime}$ and antisense strand: $5^{\prime}$-AACCAGCUAAGACACUGCCAUU- $3^{\prime}$ ), SSRNA (inhibitor) (strand: $5^{\prime}$-ACAACCAGCUAAGACACUGCCA-3'), negative control (sense strand: $5^{\prime}$-UUCUCCGAACGUGUCACGUTT- $3^{\prime}$ and antisense strand: $5^{\prime}$-ACGUGACACGUUCGGAGAATT- $3^{\prime}$, named as NC), fluorescein-labeled dsRNA ( $5^{\prime}$ end of the sense strand, FAMdsRNA), fluorescein-labeled ssRNA inhibitor ( $5^{\prime}$ end of the sense strand, FAM-ssRNA), and fluorescein-labeled negative control $\left(5^{\prime}\right.$ end of the sense strand, FAM-NC) were synthesized and purified with HPLC by Sangon Biotech Co., Ltd. (Shanghai, China). DMEM medium and PRMI 1640 medium were obtained from Macgene Technology Co., Ltd. (Beijing, China). The solvents were purchased from J\&K Scientific Ltd. (Beijing, China).

\subsection{Cell lines and experimental animals}

The human TNBC MDA-MB-231 cells, human breast cancer MCF-7 cells and mouse breast cancer 4T1 cells were obtained from Institute of Basic Medical Science, Chinese Academy of
Medical Science (Beijing, China). MDA-MB-231 cells were cultured in Dulbecco's modified Eagle medium (DMEM) medium (Macgene, Beijing, China) supplemented with 10\% fetal bovine serum (FBS), $100 \mathrm{U} \mathrm{mL}^{-1}$ penicillin, $100 \mu \mathrm{g} \mathrm{mL}$ streptomycin (Macgene, Beijing, China). MCF-7 cells and 4T1 cells were cultured in Roswell Park Memorial Institute (RPMI 1640) (Macgene, Beijing, China) supplemented with $10 \%$ FBS, $100 \mathrm{U} \mathrm{mL}^{-1}$ penicillin, $100 \mu \mathrm{g} \mathrm{mL}^{-1}$ streptomycin. MDA-MB-231 cells and MCF-7 cells were cultured in humidified atmosphere of $5 \% \mathrm{CO}_{2}$ at $37{ }^{\circ} \mathrm{C}$, while $4 \mathrm{~T} 1$ cells were cultured without $5 \%$ $\mathrm{CO}_{2}$. The cells for all experiments were in logarithmic phase of growth.

Female BALB/c nude mice of 18-20 g (6-7 weeks old) were purchased from Vital River Laboratory Animal Center (Beijing, China) and maintained in a specific pathogen free (SPF) environment. All animal experiments were carried out in accordance with guidelines, and approved by the Committee for Experimental Animal Welfare of Biomedical Ethics of Peking University.

\subsection{Synthesis of MASA}

To obtain MASA, sodium alginate was oxidized by sodium periodate. Briefly, sodium alginate $(10 \mathrm{~g})$ was dispersed in $50 \mathrm{~mL}$ absolute ethanol to prepare a suspension (liquid A), and different amounts of sodium periodate was dissolved in $50 \mathrm{~mL}$ water to prepare a solution (liquid B). Adjusting the feed ratio of liquid B to liquid A so that the molar ratio of sodium periodate to sodium alginate monomer unit was $15 \%, 20 \%, 30 \%, 40 \%$, respectively. Under stirring condition, liquid B was added into liquid A. After $30 \mathrm{~min}$, ethylene glycol which had an equivalent molar ratio of sodium periodate was added to the system for terminating the reaction. The entire reaction process was protected from light. The reaction mixture was poured into a large amount of absolute ethanol $\left(V_{\text {reaction mixture }} / V_{\text {absolute ethanol }}=1 / 5\right)$ under rapidly stirring to obtain sediment. Then the sediment was filtered and vacuum dried at $40{ }^{\circ} \mathrm{C}$ to obtain solid powders. The solid powders were transferred into a regenerated cellulose dialysis tubing (MWCO, $300 \mathrm{Da}$ ) and dialyzed against deionized water for $24 \mathrm{~h}$ to remove unreacted sodium periodate and ethylene glycol. Then the mixture was freeze dried to obtain MASA powders. The product was confirmed using MALDI-TOFMS (Shimadzu, Japan).

\subsection{Synthesis of MPEI}

To synthesize mPEI, MASA was connected with PEI using aldehyde-amine condensation. Briefly, MASA was dissolved in water to prepare solution I, and polyethyleneimine solution was dissolved in water to prepare solution II ( $\mathrm{pH}$ 6-11, adjusting $\mathrm{pH}$ value with $\mathrm{HCl}$ ). Solution I was dropped into solution II slowly under stirring condition in $0.5-2 \mathrm{~h}$, and then the mixture was stirred for another $24 \mathrm{~h}$. The mixture was transferred into a regenerated cellulose dialysis tubing and dialyzed against deionized water for $48 \mathrm{~h}$ to remove the solid insoluble matter. Then the mixture was freeze dried, and graft copolymer mPEI was obtained. The product was confirmed using MALDI-TOFMS (Shimadzu, Japan). 


\subsection{Preparation and characterization of dsRNA mPEI nanoparticles}

dsRNA mPEI nanoparticles were prepared by a static incubation. Briefly, diethyl pyrocarbonate (DEPC) water was added into dsRNA freeze-dried powder to get dsRNA working solution. dsRNA working solution and mPEI were diluted with appropriate amount of Opti-MEM reduced-serum medium separately, then they were incubated for $5 \mathrm{~min}$ at room temperature, respectively. Afterwards, the diluted dsRNA solution was added to the diluted mPEI solution, vortexed, and then incubated for $20 \mathrm{~min}$ at room temperature to obtain the dsRNA mPEI nanoparticles.

Morphology of the nanoparticles was observed by transmission electron microscopy (TEM; JEOL, Japan). Briefly, dsRNA mPEI nanoparticles samples at a concentration of $1 \mu \mathrm{M}$ dsRNA were dropped on a copper grid $\left(25 \mathrm{~mm}^{2}\right)$. Then the sample was stained with $10 \mu \mathrm{L} 2 \%$ uranyl acetate solution (Sigma-Aldrich) for $2 \mathrm{~min}$ and dried under vacuum overnight. Afterwards, a JOEL 100CX transmission electron microscope $(100 \mathrm{kV})$ was used to observe the image of the sample.

Size and zeta potential of MASA, MPEI and dsRNA MPEI nanoparticles were determined using dynamic light scattering (DLS) instrument (Malvern Zetasizer Nano ZS, Malvern, UK) at $25^{\circ} \mathrm{C}$ and at a scattering angle $90^{\circ}$. The final concentration of dsRNA was $100 \mathrm{nM}$. In order to verify the dilution stability of dsRNA mPEI nanoparticles, the nanoparticles were diluted with Opti-MEM reduced-serum mediums to different dilution ratios, and then the changes in particle sizes were measure by dynamic light scattering instrument.

\subsection{Cytotoxicity of dsRNA mPEI nanoparticles at different $\mathbf{N} / \mathbf{P}$ ratios}

Sulforhodamine B (SRB) staining assay was used to evaluate the safety of dsRNA mPEI nanoparticles at different N/P ratios. Briefly, MDA-MB-231 cells were seeded in 96-well culture plates at a density of 8000 cells per well. After $24 \mathrm{~h}$ incubation, the cells were treated with $200 \mu \mathrm{L}$ Opti-MEM reduced-serum medium containing dsRNA mPEI nanoparticles at different N/P ratios. After $4 \mathrm{~h}$ incubation, the culture medium was replaced by DMEM containing 10\% FBS, and the cells were incubated for another $24 \mathrm{~h}$. Afterwards, the culture medium was removed carefully, $100 \mu \mathrm{L} \mathrm{10 \%} \mathrm{trichloroacetic} \mathrm{acid} \mathrm{(TCA)} \mathrm{was} \mathrm{added} \mathrm{to}$ each well of culture plates, respectively. The culture plates were incubated at $4{ }^{\circ} \mathrm{C}$ for $1 \mathrm{~h}$, washed for five times with deionized water, and then dried in air. A volume of $200 \mu \mathrm{L}$ SRB solution was added into each well and allowed to stand for $30 \mathrm{~min}$ in the dark. After removing the SRB solution, the culture plates were washed five times using $1 \%$ acetic acid. After air-dying, $100 \mu \mathrm{L}$ $10 \mathrm{mM}$ Tris base solution was added into each well to solubilize the protein-bound dye. The mixture was shaken on a shaker for 30 min. The absorbance of each well was measured using Infinite F50 Microplate Reader (Tecan Group Ltd., Beijing, China) at a wavelength of $540 \mathrm{~nm}$. Survival rate was calculated with the formula: survival rate $=\left(A_{540 \mathrm{~nm}}\right.$ of treated cells $/ A_{540} \mathrm{~nm}$ of blank medium control cells) $\times 100 \%$, where $A_{540 \mathrm{~nm}}$ refers to absorbance at $540 \mathrm{~nm}$.

\subsection{Gel retardation assay}

Gel retardation assay was used to investigate the protective effect of the nanoparticles on dsRNA. Briefly, dsRNA mPEI nanoparticles at a concentration of $1 \mu \mathrm{M}$ dsRNA concentration were mixed with FBS $(1: 1, \mathrm{v} / \mathrm{v})$ and then incubated at $37^{\circ} \mathrm{C}$ for different time-points $(0,1,2,3,6,9,12,24,36$, and 48 h). After sampling, the samples were stored at $-20{ }^{\circ} \mathrm{C}$ before the assay. The loading buffer of RNA $(6 \times)$ was added to each sample, and then the sample was assayed by electrophoresis on $1 \%$ agarose gel containing $0.5 \mathrm{mg} \mathrm{mL}{ }^{-1}$ Gelred (a special luminescent dye for staining RNA; Beyotime, Beijing, China). Electrophoresis was performed at $80 \mathrm{mV}$ for $3 \mathrm{~min}$, and subsequently $100 \mathrm{mV}$ for $15 \mathrm{~min}$. These resulting gels were photographed under the Imager Quant RTECL gel imaging system (Tanon, Shanghai, China). Free dsRNA was used as the control (dsRNA $=1 \mu \mathrm{M})$.

\subsection{Invasiveness characterization of breast cancer cells}

Wound-healing assay was used to compare invasiveness of the three cancer cells. Briefly, three breast cancer cells (MDA-MB231 cells, MCF-7 cells and 4T1 cells) were counted, and seeded into 6-well culture plates at $2 \times 10^{5} /$ well. When cell monolayer was formed, and a pipettor tip was used to create a scratch on each monolayer. Culture medium $(1 \mathrm{~mL})$ was used to wash each monolayer for removing the debris after the scratch, and then $2 \mathrm{~mL}$ culture medium was added into each well for further incubation. The monolayer was photographed at day 1 and day 2 since scratch, respectively.

\subsection{Expressions of target microRNA-34a in breast cancer cells}

Quantitative real-time polymerase chain reaction (qRT-PCR) was used to measure the expressions of microRNA in the three breast cancer cells. Briefly, MDA-MB-231, MCF-7 and 4T1 cells $\left(2 \times 10^{5}\right.$ per well $)$ were seeded in 6 -well culture plates. After $48 \mathrm{~h}$ incubation, total RNA was extracted using the Triol reagent (Macgene, Beijing, China), and then reversely transcribed into cDNA with a Bulge-Loop ${ }^{\mathrm{TM}}$ miRNA RT Kit (RiboBio Co. Ltd., Guangzhou, China) using thermal cycle PCR instrument (Techne, Princeton,NJ, USA).

Afterwards, qPCR was performed using Bulge-Loop ${ }^{\mathrm{TM}}$ miRNA qPCR Kit (RiboBio Co. Ltd., Guangzhou, China) in triplicates, and data collection were performed on a real-time PCR amplifier (CFX connect, Bio-Rad, Singapore). U6 was selected as the housekeeping gene. The data were normalized according to the target microRNA-34a expression of MDA-MB231 cells.

\subsection{Cellular uptake and lysosomal escape of dsRNA mPEI nanoparticles}

Flow cytometry was used to observe the cellular uptake of dsRNA mPEI nanoparticles by breast cancer cells. Briefly, MDAMB-231 cells $\left(2 \times 10^{5}\right.$ per well $)$ were seeded in 6-well culture plates. After $24 \mathrm{~h}$ incubation, the cells were treated with FAMlabeled dsRNA mPEI nanoparticles at a final concentration of $100 \mathrm{nM}$ dsRNA and incubated at $37{ }^{\circ} \mathrm{C}$ for an additional $4 \mathrm{~h}$. 
After incubation, the cells were harvested and washed three times with pre-cooled phosphate buffered saline (PBS pH 7.4; $\mathrm{NaCl} 137 \mathrm{mmol} \mathrm{L}^{-1}$, KCl $2.7 \mathrm{mmol} \mathrm{L}^{-1}, \mathrm{Na}_{2} \mathrm{HPO}_{4} 10 \mathrm{mmol} \mathrm{L}^{-1}$ $\mathrm{KH}_{2} \mathrm{PO}_{4} 2 \mathrm{mmol} \mathrm{L}^{-1}$ ), and intracellular fluorescence intensities were immediately detected by a FACS Calibur Flow Cytometer (Becton Dickinson, San Jose, CA, USA) with the excitation wavelength of $488 \mathrm{~nm}$ and the emission wavelength of $518 \mathrm{~nm}$.

Confocal microscopy was also used to observe organelle colocalization and lysosomal escape. Briefly, MDA-MB-231 cells were seeded into glass-bottom dishes at a density of $2 \times 10^{5}$ cells per dish. The cells were incubated for $24 \mathrm{~h}$. Then the culture medium was replaced by $2 \mathrm{~mL}$ fresh Opti-MEM reducedserum medium containing FAM-labeled dsRNA mPEI nanoparticles. The final concentration of FAM-labeled dsRNA was $100 \mathrm{nM}$. After transfected for $1 \mathrm{~h}, 3 \mathrm{~h}$ and $4 \mathrm{~h}$ respectively, the cells were washed three times with PBS ( $\mathrm{pH}$ 7.4). Then, lysosome and nucleus were individually stained by lysosome tracker and Hoechst 33342 according to the manufacturer's instructions. The cells were visualized under a Leica TCS SP8 confocal fluorescence microscope (Leica Microsystems, Heidelberg, Germany).

\subsection{In vitro gene knocking-down assays}

qRT-PCR was used to measure the gene knocking-down effects of Fra-1, MMP-1 and MMP-9 at mRNA levels in the invasive MDA-MB-231 cells. Briefly, MDA-MB-231 cells $\left(2 \times 10^{5}\right.$ per well $)$ were seeded in 6-well culture plates. After $24 \mathrm{~h}$ incubation, the cells were treated with dsRNA mPEI nanoparticles at a final concentration of $100 \mathrm{nM}$ dsRNA for each, and incubated at $37{ }^{\circ} \mathrm{C}$ for an additional $4 \mathrm{~h}$. After refreshing the cell culture medium, the cells were incubated for another $12 \mathrm{~h}$ for proliferation. Total RNA was extracted using the Triol reagent, and then reversely transcribed into cDNA with a Takara Reverse Transcription System (Takara Biomedical Technology Co., Ltd., Beijing, China) using thermal cycle PCR instrument (Techne, Princeton, NJ, USA).

Afterwards, qPCR was performed using Takara qPCR Master Mix (Takara Biomedical Technology Co., Ltd., Beijing, China) in triplicates, and data collection were performed on a real-time PCR amplifier (CFX connect, Bio-Rad, Singapore). Glyceraldehyde-phosphate dehydrogenase (GAPDH) was selected as the housekeeping gene. The relative expression level for each target gene was calculated by $2^{-\left(C_{\mathrm{t}}-C_{\mathrm{c}}\right)}\left(C_{\mathrm{t}}\right.$ and $C_{\mathrm{c}}$ were the mean threshold cycle differences after normalizing to GAPDH).

Western blotting was used to measure the gene knockingdown effects of Fra-1, MMP-1 and MMP-9 at protein levels in the invasive MDA-MB-231 cells.

Briefly, MDA-MB-231 cells $\left(2 \times 10^{5}\right.$ per well $)$ were seeded in 6-well culture plates. After $24 \mathrm{~h}$ incubation, the cells were treated with dsRNA mPEI nanoparticles at a final concentration of $100 \mathrm{nM}$ dsRNA for each, and incubated at $37{ }^{\circ} \mathrm{C}$ for an additional $4 \mathrm{~h}$. After refreshing the cell culture medium, the cells were incubated for another $24 \mathrm{~h}$ for proliferation. The cells were washed with pre-cooled PBS $(\mathrm{pH} 7.4)$ for three times, digested with $0.25 \%$ trypsin and centrifuged in a $15 \mathrm{~mL}$ tube.
After washing with PBS (pH 7.4), $500 \mu \mathrm{L}$ RIPA (radio immunoprecipitation assay) lysis buffer supplemented with $2 \%$ protease inhibitor and $2 \%$ phosphatase inhibitor was added to resuspend the cells. Then, the cells were incubated on ice for $30 \mathrm{~min}$ and centrifuged in a $1.5 \mathrm{~mL}$ tube at $12000 \mathrm{~g}$ at $4{ }^{\circ} \mathrm{C}$ for $30 \mathrm{~min}$. The supernatant was collected into another centrifuge tube, and the concentration of protein was determined with a BCA protein assay kit (Beyotime, Beijing, China). Subsequently, loading buffer $(5 \times)$ was added to protein samples and boiled them for $15 \mathrm{~min}$ to denature protein. Then $20 \mathrm{mg}$ of total protein was loaded on a $10 \%$ sodium polyacrylamide gel and electrophoresed at $80 \mathrm{mV}$ for $30 \mathrm{~min}$ and at $100 \mathrm{mV}$ for $90 \mathrm{~min}$. The proteins were transferred onto PVDF membranes at $100 \mathrm{mV}$ for $80 \mathrm{~min}$, and the membranes were blocked with $5 \%$ bovine serum albumin on a shaker for $2 \mathrm{~h}$. The membranes were incubated with the Fra-1 (1:1000), MMP-1 (1:1000), MMP-9 $(1: 1000)$ and $\beta$-actin $(1: 1000)$ (Biosynthesis Biotechnology Inc., Beijing, China) monoclonal antibody on a shaker overnight at $4{ }^{\circ} \mathrm{C}$, respectively. The membranes were washed three times with TBST (tris-buffered saline and Tween 20), and then incubated with HRP-conjugated goat anti-rabbit antibodies (1:2000) (Biosynthesis Biotechnology Inc., Beijing, China) at room temperature for $1 \mathrm{~h}$. Finally, the membranes were washed three times with TBST and exposed using SageCapture ${ }^{\mathrm{TM}}$ MiniChemi610 System (Sagecreation, Beijing, China).

\subsection{Inhibition effect of dsRNA mPEI nanoparticles on invasiveness}

Wound-healing assay was used to evaluate the inhibitory effect of dsRNA mPEI nanoparticles on the migration ability of cancer cells. Briefly, MDA-MB-231 cells $\left(2 \times 10^{5}\right.$ per well $)$ were seeded in 6-well plates. For experimental group, the cells were transfected with dsRNA mPEI nanoparticles when at 50-60\% confluence, and then incubated at $37{ }^{\circ} \mathrm{C}$ until cells reached $100 \%$ confluence to form a monolayer. For control group, the cells were incubated at $37{ }^{\circ} \mathrm{C}$ until cells reached $100 \%$ confluence to form a monolayer. Afterwards, pipettor tips were used to create a scratch on each cell monolayer. Culture medium $(1 \mathrm{~mL})$ was used to wash each monolayer for removing the debris after the scratch, and then $2 \mathrm{~mL}$ culture medium was added into each well for further incubation. The monolayer was photographed at day 1 and day 2 since scratch, respectively.

Transwell invasion assay was used to observe the inhibitory effect of dsRNA mPEI nanoparticles on the invasiveness of cancer cells. Briefly, MDA-MB-231 cells were resuspended by DMEM containing $0.5 \%$ FBS to adjust cell density to $5 \times 10^{5} /$ $\mathrm{mL}$. The above cell suspension $(100 \mu \mathrm{L})$ was added into the upper chamber of $8 \mu \mathrm{m}$ transwells, and $700 \mu \mathrm{L}$ DMEM containing 35\% FBS was added into the lower chamber. For experimental group, dsRNA mPEI nanoparticles were added into the upper chamber. For blank control group, an equal amount medium was added into the upper chamber. After $10 \mathrm{~h}$ incubation, the filter side of the upper chamber was cleaned with a cotton swab and the cells were fixed with $4 \%$ paraformaldehyde at room temperature for $10 \mathrm{~min}$. Then, the filter was stained with $0.1 \%$ crystal violet for $5 \mathrm{~min}$ and rinsed in PBS 
(pH 7.4). After washing the floating violet color, the samples were photographed under the microscope.

\subsection{Anticancer efficacy and inhibitory effect on the Fra-1 relevant genes in mice}

To study the anticancer efficacy of dsRNA mPEI nanoparticles in vivo, the cancer-bearing animals were xenografted with MDAMB-231 cells in nude mice. Briefly, female BALB/c nude mice were kept in an SPF-grade sterile clean environment. The cancer-bearing mice were established by the subcutaneous injection of $2 \times 10^{6}$ cells in the right flank of mice. The cancerbearing animals were randomly divided into four groups. The animals were administrated as the designed time-points (at day $7,11,15,19,23$, and 27 since cancer cell inoculation) by intratumoral injection using the following: (1) 0.9\% physiological saline; (2) dsRNA mPEI nanoparticles ( $\left.1 \mathrm{mg} \mathrm{kg}^{-1}\right)$; (3) ssRNA mPEI nanoparticles (inhibitor of dsRNA; $2 \mathrm{mg} \mathrm{kg}^{-1}$ ); (4) paclitaxel $\left(5 \mathrm{mg} \mathrm{kg}^{-1}\right)$. The tumor volume was measured using a Vernier caliper across its longest $(L)$ and shortest $(S)$ diameters, and calculated according to the formula, $V=0.5 \times L(\mathrm{~mm})$ $\times S^{2}\left(\mathrm{~mm}^{2}\right)$. Administration was started when the tumor volume reached approximately $200 \mathrm{~mm}^{3}$.

After the start of drug administration, the body weights of mice were measured every two days. After all administrations, the mice were sacrificed by cervical dislocation. The tumors were isolated, the volumes and weights of tumors were recorded.

To evaluate the gene knocking-down effects in the cancerbearing mice, qRT-PCR assay and western blotting assay were performed on the isolated tumor tissues to determine mRNAs and proteins of the Fra-1, MMP-1 and MMP-9.

\subsection{Statistical analyses}

Data were expressed as the mean \pm standard deviation (SD). Analysis of variance (ANOVA) was used to determine the significance among groups, after which, post hoc tests with the Bonferroni correction were used for multiple comparisons between individual groups. A value of $P<0.05$ was considered as statistically significant.

\section{Conclusion}

In sum, a novel type of dsRNA mPEI nanoparticles is successfully synthesized to treat aggressive TNBC cells. They are able to effectively transfect the cells, and demonstrate a strong capability in knocking-down up-stream Fra-1 gene, and downstream MMP-1 and MMP-9 genes in TNBC cells and in TNBC cancer-bearing mice, thereby inhibiting the invasion and migration of the cells. After intratumoral injection, dsRNA mPEI nanoparticles demonstrate a robust anticancer efficacy in TNBC cancer-bearing mice, and the anticancer efficacy is superior to that of paclitaxel. In conclusion, dsRNA mPEI nanoparticles are able to effectively treat aggressive TNBC, and the mechanism studies reveal that they take effect by knockingdown of Fra-1 relevant genes, hence interfering transcription and translation of the genes, which are necessary for growth and metastasis of TNBC. Therefore, the present study offers a new and promising formulation and strategy for effective treatment of TNBC.

\section{Conflicts of interest}

The authors declare no competing financial interest.

\section{Acknowledgements}

This study was funded by Beijing Natural Science Foundation (Key Grant No. 7181004) and National Natural Science Foundation of China (Grant 81673367, and 81874303).

\section{References}

1 R. Dent, M. Trudeau, K. I. Pritchard, W. M. Hanna, H. K. Kahn, C. A. Sawka, L. A. Lickley, E. Rawlinson, P. Sun and S. A. Narod, Clin. Cancer Res., 2007, 13, 4429-4434.

2 S. E. Logue, E. P. McGrath, P. Cleary, S. Greene, K. Mnich, A. Almanza, E. Chevet, R. M. Dwyer, A. Oommen, P. Legembre, F. Godey, E. C. Madden, B. Leuzzi, J. Obacz, Q. Zeng, J. B. Patterson, R. Jager, A. M. Gorman and A. Samali, Nat. Commun., 2018, 9, 3267.

3 M. C. Cheang, D. Voduc, C. Bajdik, S. Leung, S. McKinney, S. K. Chia, C. M. Perou and T. O. Nielsen, Basal-like breast cancer defined by five biomarkers has superior prognostic value than triple-negative phenotype, Clin. Cancer Res., 2008, 14, 1368-1376.

4 A. Albergaria, S. Ricardo, F. Milanezi, V. Carneiro, I. Amendoeira, D. Vieira, J. Cameselle-Teijeiro and F. Schmitt, Nottingham Prognostic Index in triple-negative breast cancer: a reliable prognostic tool?, BMC Cancer, 2011, 11, 299.

5 R. Rupaimoole and F. J. Slack, MicroRNA therapeutics: towards a new era for the management of cancer and other diseases, Nat. Rev. Drug Discovery, 2017, 16, 203-222.

6 N. R. Christoffersen, R. Shalgi, L. B. Frankel, E. Leucci, M. Lees, M. Klausen, Y. Pilpel, F. C. Nielsen, M. Oren and A. H. Lund, p53-independent upregulation of miR-34a during oncogene-induced senescence represses MYC, Cell Death Differ., 2010, 17, 236-245.

7 V. K. Gangaraju and H. Lin, MicroRNAs: key regulators of stem cells, Nat. Rev. Mol. Cell Biol., 2009, 10, 116-125.

8 P. Bonetti, M. Climent, F. Panebianco, C. Tordonato, A. Santoro, M. J. Marzi, P. G. Pelicci, A. Ventura and F. Nicassio, Dual role for miR-34a in the control of early progenitor proliferation and commitment in the mammary gland and in breast cancer, Oncogene, 2019, 38, 360-374.

9 D. G. Zisoulis, Z. S. Kai, R. K. Chang and A. E. Pasquinelli, Autoregulation of microRNA biogenesis by let-7 and argonaute, Nature, 2012, 486, 541-544.

10 T. A. Farazi, J. I. Hoell, P. Morozov and T. Tuschl, microRNAs in human cancer, Adv. Exp. Med. Biol., 2013, 774, 1-20.

11 X. J. Li, Z. J. Ren and J. H. Tang, MicroRNA-34a: a potential therapeutic target in human cancer, Cell Death Dis., 2014, 5, e1327. 
12 H. Hermeking, The miR-34 family in cancer and apoptosis, Cell Death Differ., 2010, 17, 193-199.

13 E. Slabáková, C. Zoran, J. Remšík and K. Souček, Alternative mechanisms of miR-34a regulation in cancer, Cell Death Dis., 2017, 8, e3100.

14 L. Yu, J. Xiong, L. Guo, L. Miao, S. Liu and F. Guo, The effects of lanthanum chloride on proliferation and apoptosis of cervical cancer cells: involvement of let-7a and miR-34a microRNAs, BioMetals, 2015, 28, 879-890.

15 Y. S. Lee and A. Dutta, MicroRNAs in cancer, Annu. Rev. Pathol.: Mech. Dis., 2009, 4, 199-227.

16 M. Rokavec, H. H. Li, L. C. Jiang and H. Hermeking, The p53/ miR-34 axis in development and disease, J. Mol. Cell Biol., 2014, 6, 214-230.

17 E. Henckels and R. Prywes, Fra-1 regulation of Matrix Metallopeptidase-1 (MMP-1) in metastatic variants of MDAMB-231 breast cancer cells, F1000Research, 2013, 2, 229.

18 J. L. Pakay, J. Diesch, O. Gilan, Y. Y. Yip, E. Sayan, W. Kolch, J. M. Mariadason, R. D. Hannan, E. Tulchinsky and A. S. Dhillon, A $19 \mathrm{~S}$ proteasomal subunit cooperates with an ERK MAPK-regulated degron to regulate accumulation of Fra-1 in tumour cells, Oncogene, 2012, 31, 1817-1824.

19 A. E. Sayan, R. Stanford, R. Vickery, E. Grigorenko, J. Diesch, K. Kulbicki, R. Edwards, R. Pal, P. Greaves, I. Jariel-Encontre, M. Piechaczyk, M. Kriajevska, J. K. Mellon, A. S. Dhillon and E. Tulchinsky, Fra-1 controls motility of bladder cancer cells via transcriptional upregulation of the receptor tyrosine kinase AXL, Oncogene, 2012, 31, 1493-1503.

20 A. S. Dhillon and E. Tulchinsky, FRA-1 as a driver of tumour heterogeneity: a nexus between oncogenes and embryonic signalling pathways in cancer, Oncogene, 2015, 34, 44214428.

21 A. Philips, C. Teyssier, F. Galtier, C. Rivier-Covas, J. M. Rey, H. Rochefort and D. Chalbos, FRA-1 expression level modulates regulation of activator protein-1 activity by estradiol in breast cancer cells, Mol. Endocrinol., 1998, 12, 973-985.

22 H. Yin, K. J. Kauffman and D. G. Anderson, Delivery technologies for genome editing, Nat. Rev. Drug Discovery, 2017, 16, 387-399.

23 K. Belguise, N. Kersual, F. Galtier and D. Chalbos, FRA-1 expression level regulates proliferation and invasiveness of breast cancer cells, Oncogene, 2005, 24, 1434-1444.

24 O. Fundyler, M. Khanna and B. R. Smoller, Metalloproteinase-2 expression correlates with aggressiveness of cutaneous squamous cell carcinomas, Mod. Pathol., 2004, 17, 496-502.

25 D. Q. Matus, X. Y. Li, S. Durbin, D. Agarwal, Q. Chi, S. J. Weiss and D. R. Sherwood, In vivo identification of regulators of cell invasion across basement membranes, Sci. Signaling, 2010, 3, ra35.

26 O. Boussif, F. Lezoualc'h, M. A. Zanta, M. D. Mergny, D. Scherman, B. Demeneix and J. P. Behr, A versatile vector for gene and oligonucleotide transfer into cells in culture and in vivo: polyethylenimine, Proc. Natl. Acad. Sci. U. S. A., 1995, 92, 7297-7301.
27 A. C. R. Grayson, A. M. Doody and D. Putnam, Biophysical and structural characterization of polyethyleniminemediated siRNA deliveryin vitro, Pharm. Res., 2006, 23, 1868-1876.

28 O. Boussif, M. A. Zanta and J. P. Behr, Optimized galenics improve in vitro gene transfer with cationic molecules up to 1000-fold, Gene Ther., 1996, 3, 1074-1080.

29 D. W. Pack, A. S. Hoffman, S. Pun and P. S. Stayton, Design and development of polymers for gene delivery, Nat. Rev. Drug Discovery, 2005, 4, 581-593.

30 H. Yin, R. L. Kanasty, A. A. Eltoukhy, A. J. Vegas, J. R. Dorkin and D. G. Anderson, Non-viral vectors for gene-based therapy, Nat. Rev. Genet., 2014, 15, 541-555.

31 C. V. Pecot, G. A. Calin, R. L. Coleman, G. Lopez-Berestein and A. K. Sood, RNA interference in the clinic: Challenges and future directions, Nat. Rev. Cancer, 2011, 11, 59-67.

32 X. An, C. Sarmiento, T. Tan and H. Zhu, Regulation of multidrug resistance by microRNAs in anti-cancer therapy, Acta Pharm. Sin. B, 2017, 7, 38-51.

33 L. Kang, J. Mao, Y. Tao, B. Song, W. Ma, Y. Lu, L. Zhao, J. Li, B. Yang and L. Li, MicroRNA-34a suppresses the breast cancer stem cell-like characteristics by downregulating Notch1 pathway, Cancer Sci., 2015, 106, 700-708.

34 L. K. Medina-Kauwe, J. Xie and S. Hamm-Alvarez, Intracellular trafficking of nonviral vectors, Gene Ther., 2005, 12, 1734-1751.

35 D. A. Zajchowski, M. F. Bartholdi, Y. Gong, L. Webster, H. L. Liu, A. Munishkin, C. Beauheim, S. Harvey, S. P. Ethier and P. H. Johnson, Identification of gene expression profiles that predict the aggressive behavior of breast cancer cells, Cancer Res., 2001, 61, 5168-5178.

36 K. Gao and L. Huang, Achieving efficient RNAi therapy: progress and challenges, Acta Pharm. Sin. B, 2013, 3, 213225.

37 D. P. Bartel, MicroRNAs: genomics, biogenesis, mechanism, and function, Cell, 2004, 116, 281-297.

38 M. G. Annis, V. Ouellet, J. P. Rennhack, S. L'Esperance, C. Rancourt, A. M. Mes-Masson, E. R. Andrechek and M. Peter, Integrin-uPAR signaling leads to FRA-1 phosphorylation and enhanced breast cancer invasion, Breast Cancer Res., 2018, 20, 9.

39 S. Yang, Y. Li, J. Gao, T. Zhang, S. Li, A. Luo, H. Chen, F. Ding, X. Wang and Z. Liu, MicroRNA-34 suppresses breast cancer invasion and metastasis by directly targeting Fra-1, Oncogene, 2013, 32, 4294-4303.

40 Q. M. Wang, L. Lv, Y. Tang, L. Zhang and L. F. Wang, MMP-1 is overexpressed in triple-negative breast cancer tissues and the knockdown of MMP-1 expression inhibits tumor cell malignant behaviors in vitro, Oncol. Lett., 2019 Feb, 17, 1732-1740.

41 M. Liu, Y. Hu, M. F. Zhang, K. J. Luo, X. Y. Xie, J. Wen, J. H. Fu and H. Yang, MMP1 promotes tumor growth and metastasis in esophageal squamous cell carcinoma, Cancer Lett., 2016, 377, 97-104.

42 C. C. Liang, A. Y. Park and J. L. Guan, In vitro scratch assay: a convenient and inexpensive method for analysis of cell migration in vitro, Nat. Protoc., 2007, 2, 329-333. 
43 P. Tibarewal, G. Zilidis, L. Spinelli, N. Schurch, H. Maccario, A. Gray, N. M. Perera, L. Davidson, G. J. Barton and N. R. Leslie, PTEN protein phosphatase activity correlates with control of gene expression and invasion, a tumorsuppressing phenotype, but not with AKT activity, Sci. Signaling, 2012, 5, ra18.

44 P. Pandya, J. L. Orgaz and V. Sanz-Moreno, Modes of invasion during tumour dissemination, Mol. Oncol., 2017, 11, 5-27.

45 G. R. Jin, R. Y. He, Q. Liu, M. Lin, Y. Q. Dong, K. Li, B. Z. Tang, B. Liu and F. Xu, Near-infrared light-regulated cancer theranostic nanoplatform based on aggregationinduced emission luminogen encapsulated upconversion nanoparticles, Theranostics, 2019, 9, 246-264.

46 G. R. Jin, R. Y. He, Q. Liu, Y. Q. Dong, M. Lin, W. F. Li and F. Xu, Theranostics of triple-negative breast cancer based on conjugated polymer nanoparticles, ACS Appl. Mater. Interfaces, 2018, 10, 10634-10646.
47 G. R. Jin, G. X. Feng, W. Qin, B. Z. Tang, B. Liu and K. Li, Multifunctional organic nanoparticles with aggregationinduced emission (AIE) characteristics for targeted photodynamic therapy and RNA interference therapy, Chem. Commun., 2016, 52, 2752-2755.

48 J. Zhao, G. R. Jin, G. J. Weng, J. J. Li, J. Zhu and J. W. Zhao, Recent advances in activatable fluorescence imaging probes for tumor imaging, Drug Discovery Today, 2017 Sep, 22, 13671374.

49 J. M. Williford, J. Wu, Y. Ren, M. M. Archang, K. W. Leong and H. Q. Mao, Recent Advances in Nanoparticle-Mediated siRNA Delivery, Annu. Rev. Biomed. Eng., 2014 Jul 11, 16, 347-370.

50 H. M. Chen, W. Z. Zhang, G. Z. Zhu, J. Xie and X. Y. Chen, Rethinking cancer nanotheranostics, Nat. Rev. Mater., 2017, 2, 17024. 